\section{A. ARS BILDUMA ISSN 1989-9262 UPV/EHU Press} ARSBILDUMA (CC BY-NC-ND 4.0)

https://doi.org/10.1387/ars-bilduma.20572 BIBLID [(2019), 9; 169-189]

Recibido: 11/02/2019 Aceptado: 23/05/2019

\title{
AURELIO ARTETA, DIRECTOR DEL MUSEO DE ARTE MODERNO DE BILBAO（1924-1936）
}

\author{
AURELIO ARTETA, DIRECTOR OF THE BILBAO MODERN ART MUSEUM \\ (1924-1936)
}
AURELIO ARTETA, BILBOKO ARTE MODERNOKO MUSEOKO ZUZENDARIA (1924-1936)

RESUMEN

Creado con los fondos de arte moderno del Museo de Bellas Artes, en 1924 abrió sus puertas el Museo de Arte Moderno de Bilbao. Su director, el pintor Aurelio Arteta, orientó el museo sobre dos principios fundamentales: una política de compras regular y la organización de exposiciones temporales. A pesar de sufrir la incomprensión de las instituciones públicas, perfiló la vocación del futuro Museo de Bellas Artes de Bilbao, con la fusión de ambos tras la Guerra Civil, como una institución comprometida con la creación contemporánea de su entorno más cercano.

PALABRAS CLAVE

Museo de Bellas Artes de Bilbao; Museo de Arte Moderno de Bilbao; Aurelio Arteta Arte moderno; Arte vasco; Coleccionismo artístico.

\section{ABSTRACT}

Created with the collections of modern art of the Fine Arts Museum, in 1924 opened the Bilbao Modern Art Museum. Its director, the painter Aurelio Arteta, guided the museum on two fundamental principles: a policy of regular purchases and the organization of temporary exhibitions. Despite suffering the lack of understanding of public institutions, he outlined the vocation of the future Bilbao Fine Arts Museum, with the merger of both after the Spanish Civil War, as an institution committed to the contemporary creation of its closest environment.

KEYWORDS

Bilbao Fine Arts Museum; Bilbao Modern Art Museum; Aurelio Arteta; Modern art Basque art; Art collecting.
LABURPENA

Arte Ederren Museoko arte modernoko funtsekin sortua, 1924an Bilboko Arte Modernoko Museoa inauguratu zen. Bere zuzendariak, Aurelio Arteta margolariak, museoa oinarrizko bi printzipioren arabera orientatu zuen: erosketa politika erregular bat eta aldizkako erakusketen antolakuntza. Erakunde publikoen sentsibilitate falta sufritu arren, urte horietan zehar Artetak etorkizuneko Arte Ederren Museoa izango zenaren euskal sorkuntza garaikidearekiko bokazioa perfilatu zuen, Gerra Zibilaren ostean bi museoen fusioarekin garatuko zena.

\section{GAKO-HITZAK}

Bilboko Arte Ederren Museoa; Bilboko Arte Modernoko Museoa; Aurelio Arteta; Arte modernoa; Euskal artea; Bildumagintza artistikoa. 


\section{EL MUSEO DE BELLAS ARTES DE BILBAO (1914-1924), ENTRE LA} TRADICIÓN Y LA MODERNIDAD

El crecimiento económico consecuencia de la actividad industrial y mercantil de finales del siglo XIX, una nueva clase social con recursos suficientes y el desarrollo de las infraestructuras necesarias -sociedades culturales, exposiciones, primeras galerías, crítica de arte, asentamiento del coleccionismo particular y un conjunto artistas comprometidos con la modernidad-, dio lugar en Bilbao, durante comienzos del siglo XX, a un sistema artístico sin precedentes en el País Vasco.

En este contexto, que se caracteriza por la ausencia de un patrimonio y una tradición artística consolidada, se definió un modelo museístico distinto a otros configurados con origen en colecciones reales o estatales, impulsado por la sociedad civil y sustentado por las instituciones públicas, lo que supone una excepcionalidad en el coleccionismo público de arte a nivel estatal y erigió a Bilbao en poco tiempo en uno de los tres principales focos artísticos junto a Madrid y Barcelona. Mientras el Museo de Arte Moderno de Madrid, única institución estatal dedicada al arte contemporáneo, seguía en general anclado en el conservadurismo y en prácticas academicistas, el modelo desarrollado en Barcelona y Bilbao partía del deseo de crear un conjunto patrimonial capaz de representar una cultura nacional y contribuyó de manera importante al desarrollo de la modernidad cultural según el modelo burgués, en el caso catalán por iniciativa de los poderes oficiales locales a los que se sumaría de diversos modos la sociedad civil, y en Bilbao, a la inversa, por iniciativa de la sociedad civil a la que se sumarían los poderes oficiales locales ${ }^{1}$.

Sostenido por la Diputación Provincial de Bizkaia y el Ayuntamiento de Bilbao, en octubre de 1908 se fundó el Museo de Bellas Artes de Bilbao, que abrió sus puertas al público en febrero de 1914 en el antiguo hospital civil de Atxuri. En su inauguración contaba con una colección modesta compuesta de 137 obras, en su mayoría pinturas; 77 correspondientes a la sección de arte antiguo y 60 a la de arte moderno (Fig. 1)². Durante sus primeros diez años de trayectoria el Museo de Bellas Artes se nutrió, bajo la dirección del pintor

1 JIMÉNEZ-BLANCO, M. D.: El coleccionismo de arte en España. Una aproximación desde su historia su contexto. Barcelona, Cuadernos Arte y Mecenazgo, n. 2, Fundación Arte y Mecenazgo, 2013, p. 52.

2 La distinción entre arte antiguo y arte moderno, que sirve para diferenciar las dos secciones de las colecciones del Museo de Bellas Artes de Bilbao, responde a un habitual de dichos términos en el contexto de

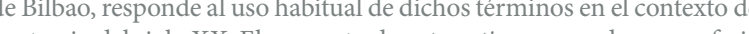
sistema artistico bilbaino del primer tercio del siglo XX. El concepto de arte antiguo es usado para referirse a todo el arte anterior al ultimo cuarto del siglo XIX, y el de arte moderno al arte que corresponde al últmo cuarto del siglo XIX y al siglo XX, correspondiente a lo que se entiende por modernidad artística. Par evitar posibles confusiones el presente artículo mantiene dicha terminología en significación originaria.
Manuel Losada, de depósitos institucionales, donaciones de coleccionistas particulares y adquisiciones. Son destacables la contribución de la Diputación, que aportó obras de arte moderno - caso de las provenientes de la I Exposición Internacional de Pintura y Escultura (1919) o el grupo de piezas de artistas vascos procedentes del III Congreso de Estudios Vascos de Gernika (1922) - y concedió partidas extraordinarias para la adquisición de obras importantes de arte antiguo -caso de pinturas de El Greco (1920) o José de Ribera (1924)-, así como la significativa cantidad que el museo recibió en concepto de donativo, entre ellas piezas destacadas como El rapto de Europa de Martin de Vos y el Retrato de la condesa Mathieu de Noailles de Ignacio Zuloaga, ambas en $1919^{3}$

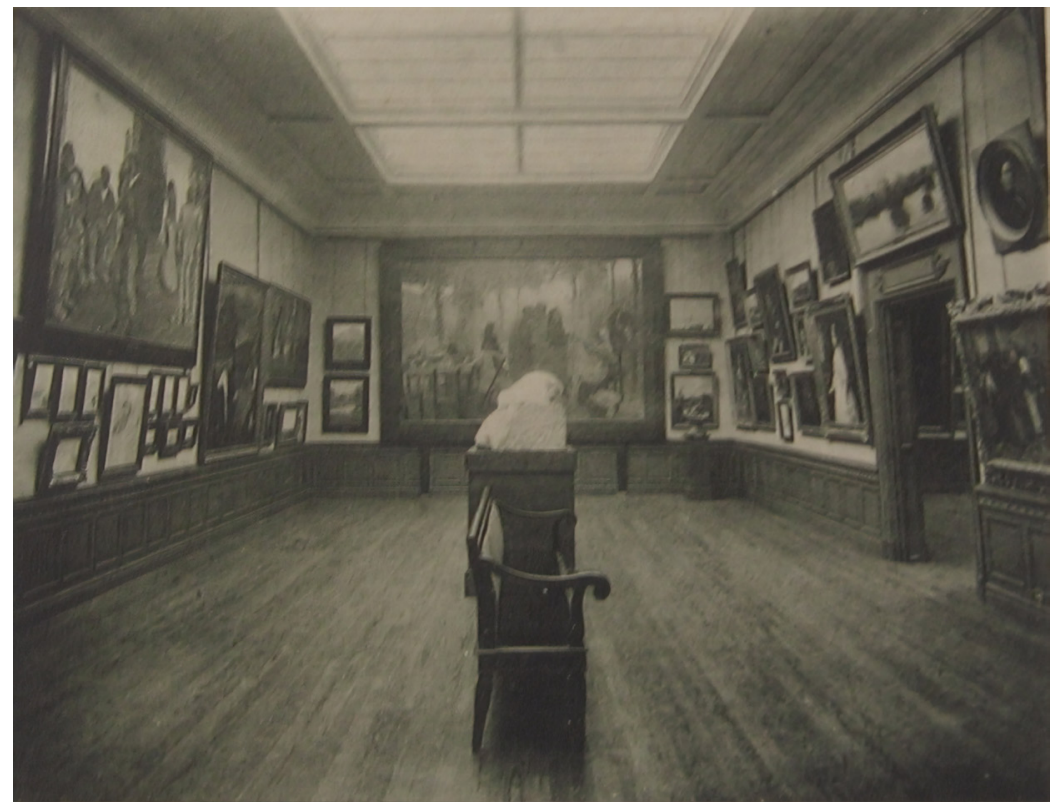

Fig 1. Sala de la sección de arte moderno en el Museo de Bellas Artes de Bilbao. Recuerdos Artísticos de Bilbao, 1919

3 Para un análisis de la génesis, creación y desarrollo de la primera colección del Museo de Bellas Artes de Bilbao ver ONANDIA, M.: Museo de Bellas Artes de Bilbao: los orígenes de una colección. Las colecciones del Museo de Bellas Artes y el Museo de Arte Moderno de Bilbao. 1908-1936 (Tesis doctoral). Bilbao, Universidad del País Vasco-Euskal Herriko Unibertsitatea, 2017. 
La mencionada Exposición Internacional de Pintura y Escultura de 1919, el evento artístico más importante que tuvo lugar en Bilbao durante el primer tercio del siglo XX, reunió má de 400 obras de cerca de 140 artistas, entre los que se contaban nombres como Manuel Losada, Darío de Regoyos, Juan de Echevarría, Pablo Uranga, Francisco Iturrino, Aurelio Arteta o Ignacio Zuloaga entre los artistas vascos; Hermen Anglada-Camarasa, Joaquim Mir, Daniel Vázquez Díaz, Pablo Picasso, Joaquim Sunyer, Pablo Gargallo, Isidro Nonell y osé Gutiérrez Solana entre los artistas españoles; así como Charles Cottet, Maurice Denis, Paul Gauguin -de quien se mostraron muchas obras, la gran mayoría propiedad de su amigo Francisco Durrio-, Vincent van Gogh, Camille Pissarro, Mary Cassatt o Auguste Renoir entre los artistas extranjeros. Se trató de una exposición de arte moderno de corte clásico sin lugar para las heterodoxias vanguardistas, que culminó el primer proceso de renovación de la plástica española entendida como la ruptura con la Academia, aportó un mportante lote de piezas al Museo de Bellas Artes y supuso un auténtico pistoletazo de salida para la creación del Museo de Arte Moderno de Bilbao.

A pesar de su vocación de contemporaneidad, a lo largo de los primeros diez años de vida se sucedieron en torno al Museo de Bellas Artes tensiones entre quienes defendían su orientación hacia el arte antiguo y quienes apoyaban convertirlo fundamentalmente en un museo de arte moderno. Si bien tradición y modernidad nunca se llegaron a considerar realidades contrapuestas e irreconciliables, en la práctica la Junta de Patronato y su director Manuel Losada apostaron por el arte más consagrado. Al mismo tiempo, como resultado de las distintas campañas promovidas por artistas y aficionados el museo recibió numerosas solicitudes para la participación en suscripciones populares gracias a las cuales ingresó obras contemporáneas, y simultáneamente fue objeto de distintas voces críticas hacia su carácter conservador.

En poco tiempo, como consecuencia de la apuesta por la creación más contemporánea de sus promotores -con apoyo de la Asociación de Artistas Vascos y de críticos como Juan de la Encina o Estanislao María de Aguirre-, y en gran medida fruto del propio Museo de Bellas Artes, en 1922 se creó a partir de los fondos de la sección de arte moderno del aquél, el Museo de Arte Moderno de Bilbao. Su director, el artista Aurelio Arteta, definió la orientación del nuevo museo en consonancia con una idea de modernidad heredada del Museo de Bellas Artes y abierta a las tendencias de los creadores más jóvenes.

El Museo de Arte Moderno, instalado en unos locales precarios y con un presupuesto modesto, tuvo que sortear numerosas dificultades. En 1927 Aurelio Arteta dimitió de su cargo tras una polémica en relación a la orientación artística del museo, lo que supuso la renuncia de varios miembros de la Junta. Todos ellos se volvieron a incorporar, como lo hiciera el director temporalmente, durante los años de la República, para continuar y desarrollar durante la década de los 30 el trabajo iniciado pocos años antes. Por su parte, con el traslado de casi la mitad de sus fondos al Museo de Arte Moderno, a partir de 1924 el Museo de Bellas Artes dio comienzo a una nueva etapa centrado en exclusiva en el arte antiguo y la colección comenzó a aumentar de manera considerable, con importantes adquisiciones y depósitos, legados y donaciones de coleccionistas particulares como Antonio Plasencia, Eugenio L. Bayo o Laureano de Jado. Aquellas tres décadas anteriores a la Guerra Civil definieron las bases del actual Museo de Bellas Artes de Bilbao.

\section{AURELIO ARTETA, UN PINTOR COMPROMETIDO CON LA MODERNIDAD}

Aurelio Arteta (Bilbao, 1879 - México, 1940), pintor continuador de las tendencias pictóricas modernas y alejado de las experimentaciones vanguardistas, fue uno de los principales artistas del primer tercio del siglo XX en el País Vasco. Formado en Bilbao, Valladolid y Madrid, tras distintas estancias en París e Italia desarrolló un tipo de plástica de formas rotundas y cúbicas de tradición cezanniana y cubista con una clara tendencia al clasicismo. Arteta abordó temas sociales - paisajes urbanos, obreros, vistas industriales- $y$ escenas vascas -aldeanos, marineros- en las que lo popular y la tradición eran tratados con un estilo muy personal, cercano al simbolismo en un principio, y con tendencia hacia la geometría y la sintetización de formas más adelante.

Como ha apuntado Edorta Kortadi, la mayoría de los estudiosos dela obra de Arteta advierten tres diferentes influencias tras su paso por París: la ondulada y precisa línea de ToulouseLautrec, el primitivismo de Paul Gauguin y el sentido alegórico de las visiones clásicas de Puvis de Chavanes ${ }^{4}$. Perteneciente a la segunda generación de artistas vascos modernos, en poco tiempo se erige en uno de los principales representantes del novecentismo en el País Vasco junto a los hermanos Zubiaurre, Julián de Tellaeche, Juan de Echevarría, Antonio Guezala o los hermanos Arrúe, siendo uno de los que mejor equilibró novedad y tradición ${ }^{5}$. Arteta se convirtió en un referente para muchos de sus contemporáneos y la siguiente

KORTADI, E. "Aurelio Arteta entre la Renovación y las Vanguardias" en Aurelio Arteta : una mirad esencial, 1879-1940. Bilbao, Museo de Bellas Artes de Bilbao, 1998, p. 43.

MANTEROLA, I.: Hermes y los pintores vascos de su tiempo. Bilbao, Bizkaiko Foru Aldundia, Kultura Saila = Diputación Foral de Bizkaia, Departamento de Cultura, 2006, p. 358. 
generación de artistas locales, y su influencia se alargó durante la década de los años treinta, cuando durante la República en la provincia se formalizó lingüísticamente un tipo de pintura limpia, precisa y estructurada según esquemas geometrizados y sintetizados

Arteta fue siempre un artista comprometido con la modernidad, tanto en su producción pictórica como en su activa labor en favor del desarrollo de una cultura artística moderna en el Bilbao de las décadas de los años diez y veinte. A pesar de su escasa actividad expositiva estuvo presente en muestras colectivas importantes, como la Exposición Internacional de Pintura y Escultura de 1919 en Bilbao, en la Exhibition of Spanish Paintings en la Royal Academy de Londres en 1920 y en la I Exposición de Artistas Ibéricos en Madrid en 1925 y llegó a ser ampliamente respetado por su trabajo como pintor, ilustrador y diseñador a nivel local y estatal. Fue uno de los miembros fundadores de la Asociación de Artistas Vascos en 1911, en cuyas exposiciones colectivas estuvo presente con regularidad hast 1929, y participó activamente en diferentes iniciativas artísticas y en las suscripcione populares de las pinturas El ciego de Calatañazor de Gustavo de Maeztu, en 1917, Retrato de Miguel de Unamuno de Daniel Vázquez Díaz, en 1920, o Interior de Cristóbal Ruiz, en 1921, para su ingreso en el Museo de Bellas Artes de Bilbao, cuya sección de arte moderno también contaba con obras de Arteta.

El Museo de Bellas Artes había ingresado para su inauguración en 1914 dos pinturas del artista. Pórtico (c. 1905; n. ${ }^{\circ}$ inv. 82/159) es un depósito de la Diputación vizcaína, entregada por el pintor en 1906 como pago por su pensión y considerada como obra inaugural del costumbrismo artetiano ${ }^{7}$. Por su parte, La galerna (c. 1910-12; n. ${ }^{\circ}$ inv. 82/530) (Fig. 2), que retrata a unos pescadores observando la tormenta que se avecina, llegó al museo como depósito del Ayuntamiento de Bilbao tras haber sido adquirida en la I Exposición de Arte Moderno organizada por la Asociación de Artistas Vascos en la Sociedad Filarmónica en $1912^{8}$. Ambas pasaron al Museo de Arte Moderno en 1924, que no llegaría a ingresar más obras de Aurelio Arteta hasta la segunda mitad de la década de los años 30, cuando aquél ya no estaba a cargo de su dirección. Tras la Guerra Civil, el Museo de Bellas Artes continuó completando sus fondos con obras de Arteta, hasta convertirse en la institución que de manera más completa representa la producción del pintor bilbaíno.

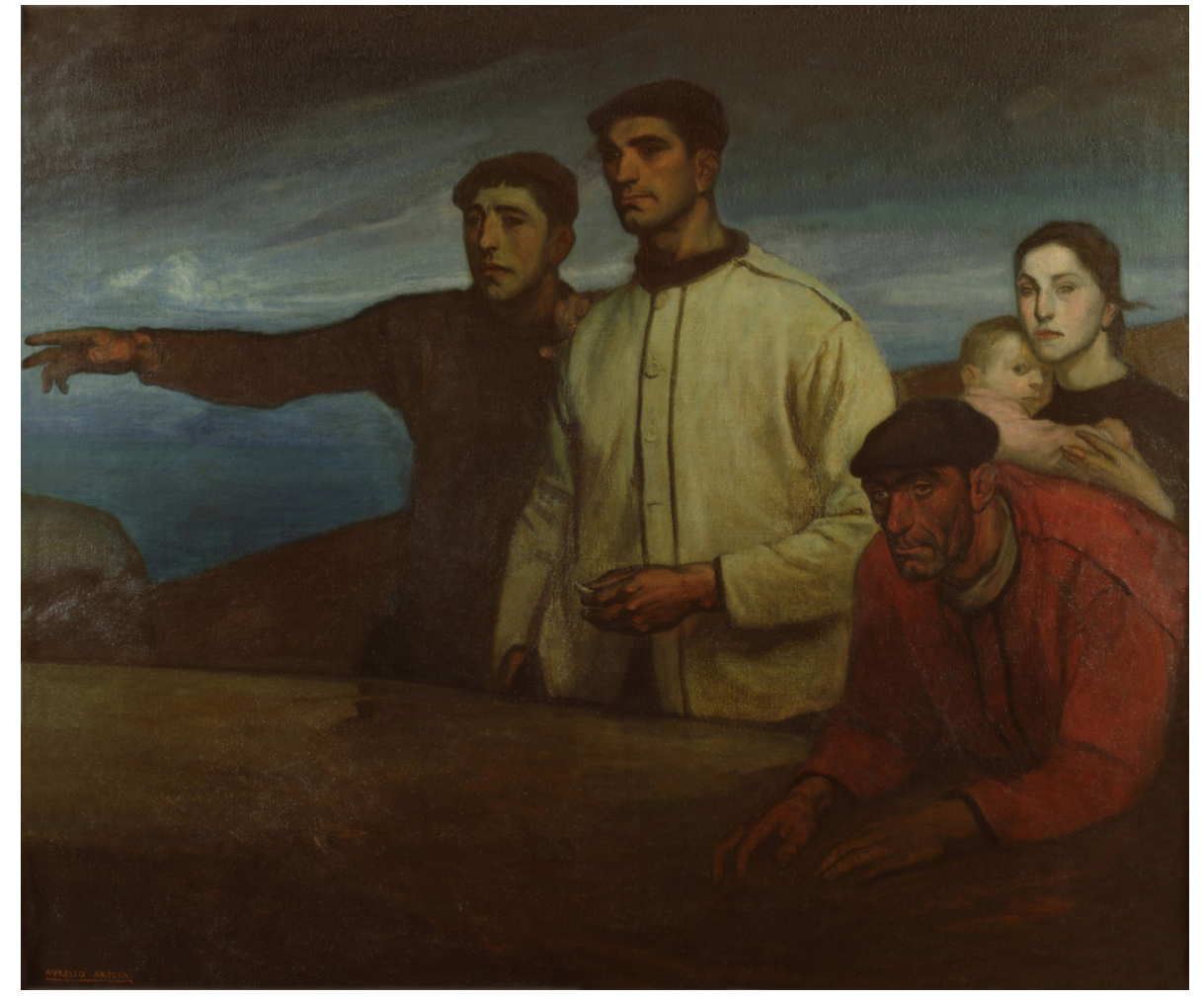

Fig. 2: La galerna, Aurelio Arteta, c. 1910-12; n.o inv. 82/530. Museo de Bellas Artes de Bilbao

6 SÁENZ DE GORBEA, X. "Crónica de hechos y prácticas artísticas en Vizcaya. 1931/1937", en Arte $y$ artistas vascos de los años 30. Entre lo individual y lo colectivo. San Sebastián, Diputación Foral de Gipuzkoa, 1986, p. 253

GONZÁLEZ DE DURANA, J.: Aurelio Arteta. Madrid, Fundación Mapfre, Instituto de Cultura, 2008, p. 20

8 MANTEROLA, I.: "Hermes y los pintores...", op. cit., p. 364 


\section{EL MUSEO DE ARTE MODERNO DE BILBAO: CREACIÓN Y PRIMERA COLECCIÓN}

En marzo de 1923 la Diputación Provincial de Vizcaya aprobó la moción de Lorenzo Hurtado de Saracho, diputado y miembro de la Junta de Patronato del Museo de Bellas Artes, presentada en octubre del año anterior para la creación en Bilbao de un Museo de Arte Moderno que tuviera como objeto exclusivo la producción artística más contemporánea, con el argumento de que el Museo de Bellas Artes no podía dedicar recursos a las tendencias modernas debido a su principal orientación de coleccionar obras escogidas de autores consagrados?.

La creación del Museo de Arte Moderno resultó muy rápida. Al igual que el Museo de Bellas Artes, era propiedad a partes iguales de la Diputación Provincial de Vizcaya y del Ayuntamiento de Bilbao. Estaba regido y administrado por una Junta de Patronato que funcionaba con total autonomía y tenía a su cargo la administración de los fondos que se pusieran a su disposición para adquisiciones, nombramiento del director y demás gestiones internas. El 31 de octubre de 1923 se constituyó la primera Junta, compuesta por el Presidente de la Diputación, el Alcalde de Bilbao, dos diputados y dos concejales, y un grupo de ocho vocales vecinos compuesto por Gregorio de Ybarra, Joaquín Zuazagoitia, Alejandro de la Sota, Ricardo Gortázar, José Félix de Lequerica, Ramón Aras Jáuregui, Eugenio Leal y Antonio Guezala, grupo que se había encargado de redactar el reglamento y que se erigiría en el verdadero alma mater del museo junto a su director. El preámbulo del mismo, redactado por Joaquín Zuazagoitia como una declaración de intenciones, subrayaba su carácter constante de vanguardia y contemporaneidad, incluyendo el riesgo de la equivocación, lo que lo diferenciaba claramente del criterio conservador que guiaba al Museo de Bellas Artes ${ }^{10}$

Archivo de la Diputación Foral de Bizkaia (ADFB): Educación, Deportes y turismo, C-995-exp-10.

10 El preámbulo del Reglamento del Museo de Arte Moderno dice así: 'Este Museo, de acuerdo con el espíritu de la Moción que para crearlo presentó el Diputado don Lorenzo Hurtado de Saracho, debe, ante todo, tener un carácter constante de contemporaneidad. Es decir, que mantendrá en todo tiempo una decidida preferencia por lo que hoy se ha dado en llamar escuelas de vanguardia, sin olvidar, claro está, aquellas manifestaciones que por su calidad merecen ser recogidas, aunque su tendencia no sea decididamente renovadora. Sin embargo, son los primeros, incluso por sus errores, los que mejor caracterizan una época.

Deberá ser nuestro Museo una antena sensible a todos los mensajes por alejados y extraños que parezcan. Su puesto de centinela le obligará a correr todos los riesgos, hasta el de la equivocación. Podemo así estar bastante bien informados del movimiento artístico del mundo y, sobre todo, podrán estarlo lo artistas que se inicien.' Archivo del Museo de Bellas Artes de Bilbao (AMBA): I Reglamento del Museo de Arte Moderno: 1923
Al igual que en Barcelona con el Museu d'Art Modern y en Madrid con el Museo de Arte Moderno, creados en 1891 y 1894 respectivamente, Bilbao contaba con un museo dedicado específicamente al arte moderno, inaugurado diez años después de la apertura del Museo de Bellas Artes. Las producciones artísticas más contemporáneas ya tenían, más allá de algunas galerías comerciales y locales de asociaciones de artistas, un lugar donde descansar y exhibirse, con el carácter oficial y académico que confería una institución museística. $\mathrm{Su}$ apertura coincide con el intento de recuperación de la crisis que tuvo lugar durante los comienzos de la década de los años 20 tras el gran florecimiento de la cultura artística en Bilbao en los años 10. El mercado artístico volvía poco a poco a moverse de nuevo y la Asociación de Artistas Vascos comenzó, tras el apoyo económico de la Diputación, un periodo de recuperación que supuso de nuevo la programación de interesantes exposiciones. Al mismo tiempo, tuvo lugar la aparición y desarrollo de un nuevo grupo de creadores -entre los que cabe destacar a Juan de Aranoa, Jenaro Urrutia, José Benito Bikandi, Jesús Olasagasti y José María Ucelay- herederos de la generación anterior y, con distintos matices, continuadores de la idea de consecución de un arte vasco moderno. Se trata de la generación más joven de artistas anteriores a la Guerra Civil, en gran medida protagonista de cierta inflexión vanguardista y partícipe de la 'vuelta al orden' que vivió la modernidad con París como epicentro, que en poco tiempo conseguiría auparse al puesto principal entre los artistas vascos y encontraría su sitio en el Museo de Arte Moderno.

En general, el Museo de Arte Moderno recibió menos dinero que el Museo de Bellas Artes -que además de contar con mayores aportaciones, obtuvo distintas consignaciones extraordinarias para adquisiciones- y tuvo más problemas con las subvenciones, por las demoras en los pagos y porque también sufrió algunas reducciones. Igualmente es de destacar que recibió mayores cantidades económicas por parte de la Diputación que por parte del Ayuntamiento, que mostró menor interés por el Museo de Arte Moderno. Las relaciones entre la Diputación y la Junta del Museo de Arte Moderno fueron mutuas y permanentes, principalmente por medio de la Junta de Cultura Vasca, principal promotora de la cultura y las artes en la provincia tras su creación en 1917. La corporación provincial consultó al museo sobre posibles adquisiciones para su depósito, y a su vez la Junta de Patronato pidió a la Diputación la adquisición de obras concretas.

El Museo de Arte Moderno se situó detrás del Palacio de la Diputación en un edificio que estaba construyendo la corporación tras la adquisición de unas viviendas situadas en la misma parcela, en la calle Rodríguez Arias, destinada a acoger la Biblioteca, el Archivo y la Imprenta Provincial, actualmente ocupado por la Biblioteca Foral. Ante las gestiones infructuosas para lograr un local propio -la moción de Hurtado de Saracho proponía la opción de ubicarlo en las Escuelas de Berástegui, aunque aquel intento fracasó, al igual que 
había fracasado poco antes el proyecto para la creación de un Palacio de los Museos-, la Junta de Patronato del Museo de Arte Moderno solicitó a la Diputación algún local en e citado edificio en noviembre de 1923, donde se instaló tras unas breves intervenciones ${ }^{12}$.

El Museo de Arte Moderno fue inaugurado, con presencia de cargos institucionales, el 25 de octubre de 1924. Los invitados, entre ellos numerosos artistas y aficionados, recorrieron las salas guiados por los miembros de la Junta de Patronato y el director Aurelio Arteta (Fig. 3). Según la prensa se expusieron unos 40 cuadros y varias esculturas, esmaltes cerámicas, entre las cuales los cronistas destacaron las piezas de Julio Antonio, Nemesio Mogrobejo, Hermen Anglada Camarasa, Daniel Vázquez Díaz, Julián de Tellaeche, Juan de Echevarría, Gustavo de Maeztu, Jenaro Urrutia, Darío de Regoyos y Francisco Iturrino ${ }^{12}$.

Como ya ha sido indicado, la primera colección del Museo de Arte Moderno se nutrió fundamentalmente de obras procedentes del Museo de Bellas Artes, concretamente con las obras de autores vivos o las de los muertos hacía menos de treinta años pertenecientes a sus fondos, con algunas excepciones, tanto por razones artísticas como por razones de espacio. Y es que el Museo de Bellas Artes se reservó el derecho de conservar bajo su patrocinio aquellas que considerara oportunas, así como la futura selección del grupo de obras que quisiera recuperar para sus fondos, por considerarlas obras consagradas ${ }^{13}$. Fue el caso de las tres pinturas de Ignacio Zuloaga con las que contaba el Museo de Bellas Artes, que

11 Durante los años siguientes el Museo de Arte Moderno de Bilbao padeció, al igual que el Museo de Bellas Artes, importantes problemas de falta de espacio. Si bien desde el principio estaba considerado como provisional y la Junta de Patronato del museo se sumó a todas la iniciativas para la construcció de un nuevo inmueble o traslado a otra estancia más amplia el Museo de Arte Moderno nuncalleǵa a difrute de in del nuevo difcio en Parte deportes y turismo, C-993-36; 995-exp-10; C-993-exp-37; MUR, P.: La Asociación de Artistas Vascos. Bilbao, Museo de Bellas Artes de Bilbao : Caja de Ahorros Vizcaína, 1985, p. 103.

12 El Noticiero Bilbaíno, 26/10/1924; El Pueblo Vasco, 26/10/1924; El Nervión, 25/10/1924. AMBA: CI-D (1924: 131); CD-582

13 Los artículos correspondientes a este respecto quedaron redactados de la siguiente manera: Art. 15: "Después de transcurridos treinta años del fallecimiento de un artista de quien posea obras el Museo

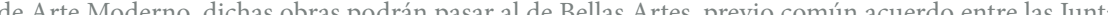
de Arte Moderno dichas obras podrán pasar al de Bellas Artes, previo conin ache junt de an Juntas, podrá pasar al Museo de Belas Artes antes de transcurrido el plazo a que se refiere el artículo anterior'. AMBA: I Reglamento del Museo de Arte Moderno; A. TI, p. 129; CD-540; CI-D (1922: 85); ADFB: Educación, deportes y turismo, C-995-exp-10 quedaron en su poder. Tampoco llegaron al Museo de Arte Moderno algunas esculturas de Nemesio Mogrobejo, Moisés de Huerta o Quintín de Torre, debido a la reducida capacidad de sus locales ${ }^{14}$. En total, el Museo de Arte Moderno recibió 98 obras procedentes del Museo de Bellas Artes.

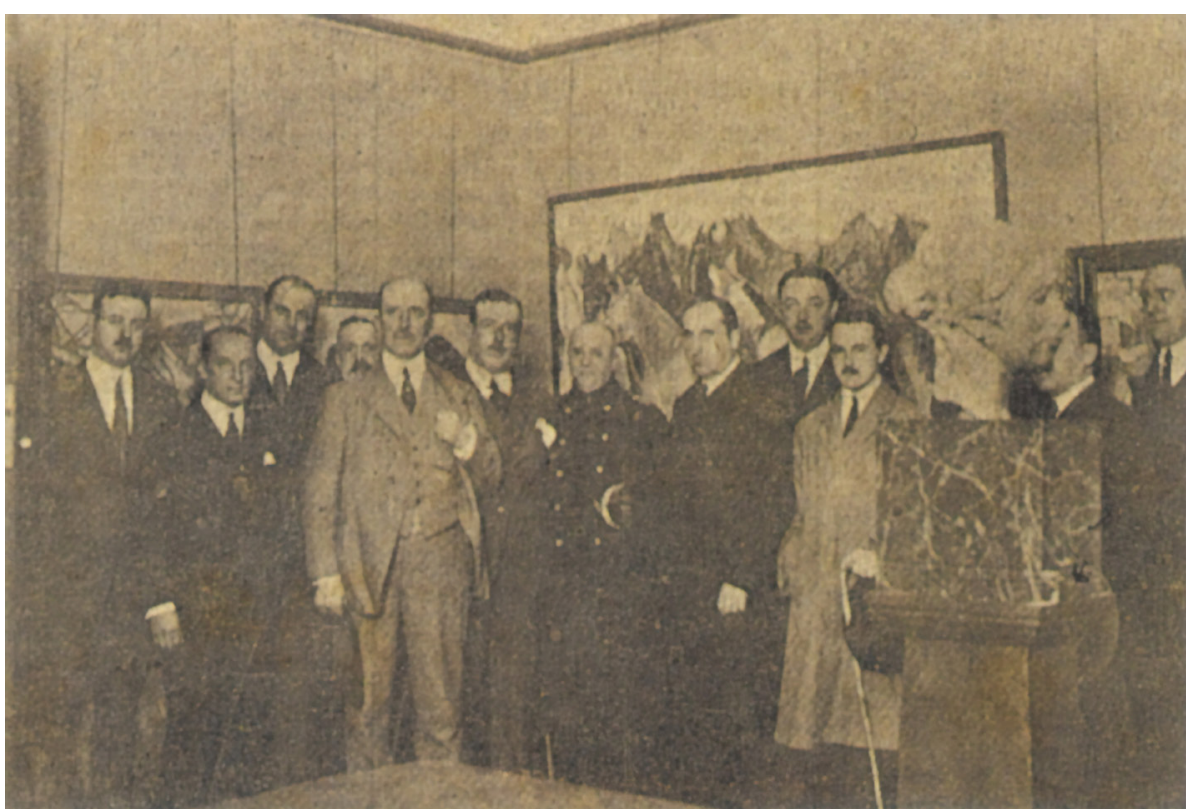

Fig. 3: Inauguración del Museo de Arte Moderno de Bilbao. El Noticiero Bilbaíno, 26/10/192

14 Se trataba de La muerte de Orfeo, Risveglio, Maternidad y Eva de Nemesio Mogrobejo, Una hetaira de Moisés de Huerta y Cargador de Bilbao de Quintín de Torre. Sin embargo, sí que pasaron algunas otras piezas escultóricas, concretamente La Venus mediterránea de Julio Antonio, Ricarda Villamor Acedo de Joan Borrell, Cabeza de San Juan Bautista de Antonio Susillo, El mirón de Moisés de Huerta y el Busto del pintor Anselmo Guinea de Nemesio Mogrobejo. AMBA: MBA/A. TII, p. 8; MBA/M (1924: 1). 
A su vez, la Junta de Patronato gestionó con la Junta de Cultura Vasca de la Diputación la devolución de algunas pinturas -piezas de autores como Alberto Arrúe, Inocencio García Asarta, José Echenagusia, Jaime Morera, Ignacio Uriarte, Pablo Uranga y Ramón Zubiaurre, probablemente devueltas debido a su menor interés artístico y a las grandes dimensiones de algunas de ellas-, así como el depósito de siete nuevas obras procedentes de exposiciones que tuvieron lugar durante aquellos años en la Sociedad Filarmónica en la Asociación de Artistas Vascos de los artistas Juan de Echevarría (Fig. 4), José Benito Bikandi, Jenaro Urrutia y Julián de Tellaeche ${ }^{15}$.

El mismo año de su creación el Museo de Arte Moderno llevó a cabo las primeras compras. Adquirió un lote de 15 joyas al escultor Francisco Durrio, un grupo de esmaltes a Ricardo Arrúe, y pinturas de Cristóbal Ruiz, Daniel Vázquez Díaz -ésta última procedente de la muestra que el pintor celebró en noviembre de 1924 en la Asociación de Artistas Vascos-, así como distintas obras de artistas extranjeros. En diciembre de 1924 el museo adquirió 4 pinturas en París de los artistas Roland Oudot, Louis Robert Antral, Jean Berque y Eugène Zak. Y a lo largo de 1924 también recibió cuatro obras en donación. Por un lado, como agradecimiento a la adquisición de sus obras, donaron piezas los artistas Ricardo Arrúe y Daniel Vázquez Díaz, y a su vez también recibió como donación una pintura de Francisco Iturrino.

En suma, el Museo de Arte Moderno contaba el año de su apertura, en esencia gracias a las aportaciones del Museo de Bellas Artes, con una colección que ascendía a 137 obras, con una amplia mayoría de piezas, muchas de ellas de primer nivel, de artistas vascos consagrados -Adolfo Guiard, Anselmo Guinea, Francisco Iturrino, Darío de Regoyos, Aurelio Arteta, los hermanos Zubiaurre- y un selecto lote de artistas nacionales -Hermen Anglada Camarasa, Joaquín Sorolla, Julio Antonio, Daniel Vázquez Díaz- e internacionales -Paul Serusier, Mary Cassatt, Paul Gauguin-, que iría completándose a lo largo de los años siguientes con más adquisiciones, donaciones y depósitos.

Poco después de ser inaugurado, distintas voces autorizadas mostraron su esperanza en el Museo de Arte Moderno. Es el caso de Juan de la Encina -uno de los principales críticos con la orientación conservadora del Museo de Bellas Artes durante la década de los años 10 y gran defensor de la pintura de Arteta- ${ }^{16}$, quien subrayó su imbricación social y le auguró

15 AMBA: CD-614: CI-D (1924: 120); ADFB: Educación, deportes y turismo, C-993-exp-33.

16 Para una selección de escritos de Juan de la Encina sobre la obra de Arteta ver la recopilación de textos realizada por Miriam Alzuri en DE LA ENCINA, J.: Pintores vascos. Comentarios sueltos. Bilbao, El Tilo 1997, pp. $143-180$

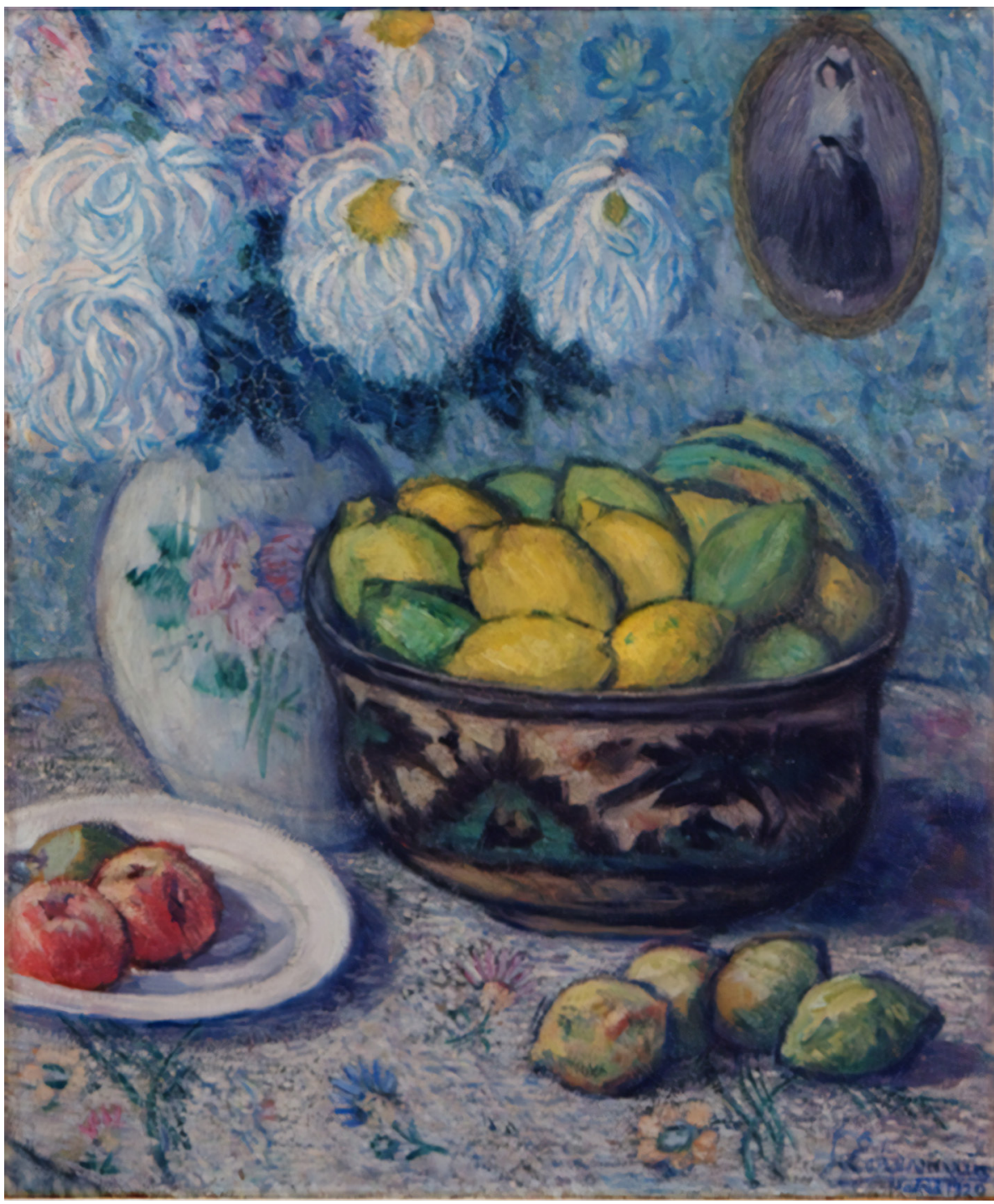

Fig. 4: Bodegón de los limones, Juan de Echevarría, 1920; n. ${ }^{\circ}$ inv. 82/119. Museo de Bellas Artes de Bilbao 
un prometedor futuro, dejando al mismo tiempo testimonio de las tensiones que surgieron en torno a su orientación desde su nacimiento. De la Encina se refirió en años siguiente en distintas ocasiones, desde las páginas del diario madrileño La Voz, al Museo de Arte Moderno de Bilbao, en un primer momento destacando su valor y necesidad, y desde un claro escepticismo a partir de la dimisión de $\operatorname{Arteta}^{17}$

\section{AURELIO ARTETA, DiRECTOR DEL MUSEO DE ARTE MODERNO}

Aurelio Arteta fue nombrado director del Museo de Arte Moderno el 3 de enero de 1924 y tomó posesión del cargo el 20 de marzo de ese $\mathrm{año}^{18}$. El artista bilbaíno jugó un importante papel en la creación y posterior evolución del museo, si bien es cierto que su labor se vio condicionada e interrumpida por las carencias económicas y materiales de la recién creada institución, en un primer momento en 1927 por la polémica con el Ayuntamiento, y más adelante con la excedencia solicitada para dedicarse a la enseñanza en Madrid tras su retorno a comienzos de la década de los 30, lo que limitó a Arteta a la hora de definir aplicar de manera constante y rigurosa su impronta personal. Sin embargo, a pesar de las dificultades su implicación en la gestión y dirección fue determinante en la orientación y posterior evolución del Museo de Arte Moderno.

Cuando Aurelio Arteta se hizo cargo del museo bilbaíno, por cuya creación había trabajado junto a otros artistas desde la Asociación de Artistas Vascos durante los años anteriores, se encontraba en su mejor momento profesional como artista. Ese mismo 1924 Eugenio D’Ors elogió en Mi Salón de Otoño la obra de Arteta. Poco antes, en la primavera de 1923 había inaugurado la decoración mural de la rotonda del nuevo edificio del Banco Bilbao

17 En un artículo publicado en La Voz el 7 de agosto de 1925, Juan de la Encina afirma: 'Así como el Museo antiguo aparecía en Bilbao como un islote remoto, sin apenas conexión con el ambiente artístico de la villa -un poco laxo, eso sí; pero al fin y al cabo, vivo y de su tiempo-, el Museo moderno vive al día de todas las inquietudes artísticas del ambiente en que ha surgido. Se discuten continuamente sus adquisiciones -a las veces se pide también, por los de la acera de enfrente, las cabezas del director y de los señores de la Junta sin reparar que son de calidad más fina y fuerte y honesta que las de tantos financieros

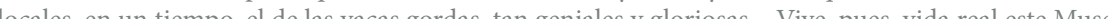
locales, en tiempo, elde las vacusor y no fantasmagorica, y van a su recinto y de el parten constantes estinulos de produccion artistica. En realidad, es un interesante ensayo de establecimiento en España de un Museo de arte genuinamente actual'. La Voz, 07/08/1925; 18/08/1925; 29/04/1929.

18 AMBA: CD-675; 677 en Madrid, obra del arquitecto Ricardo Bastida. Se trata de una obra admirada por sus contemporáneos y considerada como una de las obras culminantes del pintor, que consolida definitivamente su carrera y difunde su firma entre la crítica y los aficionados españoles ${ }^{19}$.

Tal y como ha sido señalado por Javier González de Durana, Aurelio Arteta reunía en su persona la capacidad crítica y el conocimiento artístico suficientes para encarar la dirección del Museo de Arte Moderno ${ }^{20}$. La Junta de Patronato apostó, como en el caso del Museo de Bellas Artes con Manuel Losada, por un artista - práctica habitual en distintos países europeos a lo largo del siglo XIX y aún a comienzos del siglo XX, a falta de una universidad que procurara la profesionalización de la historiografía del arte y la museología-, conocedor del ambiente artístico local y que se identificaba con los postulados que defendía la misma. En este sentido, el hecho de que los directores de los dos museos bilbaínos fueran pintores en activo facilitó y potenció las relaciones con los demás artistas del entorno, con especial intensidad con Ignacio Zuloaga y Francisco Durrio en el caso del Museo de Bellas Artes de la mano de Manuel Losada, y con las nuevas generaciones de artistas vascos en el caso del Museo de Arte Moderno de la mano de Aurelio Arteta.

Haciendo suyo el encargo de la Junta de Patronato, Arteta definió las bases del Museo de Arte Moderno sin rupturas significativas con la orientación de la sección de arte moderno del Museo de Bellas Artes y se adecuó a la nueva realidad artística de los años 20 a partir de dos grandes líneas de actuación: una política de adquisiciones regular y la organización de exposiciones de arte contemporáneo con objeto de dar a conocer a jóvenes creadores y obtener de ese modo obras para los fondos del museo.

\subsection{Política de adquisiciones. Ofertas y primeras compras}

Una vez creado el Museo de Arte Moderno la Junta de Patronato se puso en marcha para la adquisición de nuevas piezas, y en seguida comenzó a recibir ofertas para la adquisición de obras $^{21}$. El Museo de Arte Moderno compró obras tanto en exposiciones, principalmente en las celebradas en la Asociación de Artistas Vascos, así como entre las ofrecidas por coleccionistas, por artistas o por sus familiares, piezas de creadores ya representados en la colección -procedentes del Museo de Bellas Artes- y de otros de los que no poseía obra.

19 KORTADI, E. op cit, p. 62; MANTEROLA, I. "Hermes y los pintores. ." op. cit. p. 381.

20 GONZÁLEZ DE DURANA, J.: "Aurelio Arteta", op. cit., p. 86.

21 Según la memoria de ese año, 'desde que la Junta quedó constituida se preocupó grandemente de la adquisición de obras de arte'. Al igual que la Junta de Patronato del Museo de Bellas Artes, la Junta del Museo de Arte Moderno funcionaba mediante ofertas recibidas, informaciones de oportunidades 
Tras su inauguración el museo compró, tal y como se ha señalado con anterioridad, algunas pocas obras de artistas extranjeros. Se trata concretamente de cuatro pinturas, dos paisaje urbanos de Louis Robert Antral y Roland Oudot, un desnudo de Jean Berque y una escena de guiñoles de Eugène Zak, todas ellas composiciones tendentes a la geometrización y sintetización tan del gusto de Aurelio Arteta (Fig. 5) ${ }^{22}$. También existe constancia del intento de adquisición de más obras de artistas internacionales -caso de Tsuguharu Foujita, Marie Laurencin y Raoul Dufy_ ${ }^{23}$, así como de distintos rechazos a ofertas que llegaban a la Junta de Patronato

Es conocido el ofrecimiento que llegó al museo en enero de 1924 por parte de Francisco Durrio -quien durante aquellos años también ofreció desde París piezas de artistas como Odilon Redon, Gustave Courbet o Adolphe Monticelli al Museo de Arte Moderno de distintas obras de arte antiguo al Museo de Bellas Artes- de un lote de 120 obras de Paul Gauguin compuesto por óleos, acuarelas, guaches, dibujos, grabados y litografías, en un precio de 150.000 francos. Durrio -amigo íntimo del pintor francés, que se había quedado con una parte significativa de su obra-, propuso al museo bilbaíno dedicar una sala entera a Gauguin, algo inédito en el mundo, para lo que se podría llevar a cabo una suscripción popular. En palabras del escultor, su colección abarcaba todas sus épocas, con obras realizadas en París, Bretaña, Arlés, Martinica y, en su mayoría, en Tahití, y al parecer algunos museos ya estaban interesados en su adquisición. En marzo de ese año la Junta de Patronato del museo bilbaíno rechazó la oferta con el argumento de que contaba con recursos muy escasos y no confiaba en la suscripción popular propuesta, aunque mostró su interés por si en un futuro aquél estuviera interesado en vender las obras por lotes o sueltas. El Museo de Arte Moderno no supo ver la gran oportunidad que brindaba la ofert del escultor, que hubiera supuesto un ingreso con implicaciones difíciles de imaginar en el futuro, a pesar de su interés en el artista, ya que durante aquellos meses también gestionó

aportadas por sus miembros o por amistades de los mismos. Ejemplo de esto último es que Ramón de la Sota, ante un viaje a Inglaterra para varios meses a comienzos de 1924, anunció a Gregorio de Ybarra de que se informaría de la situación para la adquisición de cuadros modernos con destino al nuevo museo. AMBA: MAM/M (1924); CD-667

22 Si bien no ha sido estudiada hasta el momento, se ha sugerido la posible relación pictórica entre Arteta y Roland Oudot. Javier de Bengoechea apuntó el parentesco entre la pintura adquirida por Arteta para el Museo de Arte Moderno Paisaje de Nozay y una de sus principales obras de la década de los años 20 El puente de Burceña (c. 1925-1930; n. inv.: 82/162). BENGOECHEA, ..: Museo de Bellas Artes de Bilbao. Bilbao, La Gran Enciclopedia Vasca, 1978. p. 302

23 AMBA: MAM/M (1924: 3 ) la oferta de una pintura de Gauguin -de quien ya contaba con Lavanderas en Arlés tras su adquisición en la I Exposición Internacional de Pintura y Escultura de 1919-, ofrecida por medio de Estanislao María de Aguirre y que finalmente desechó por razones económicas ${ }^{24}$

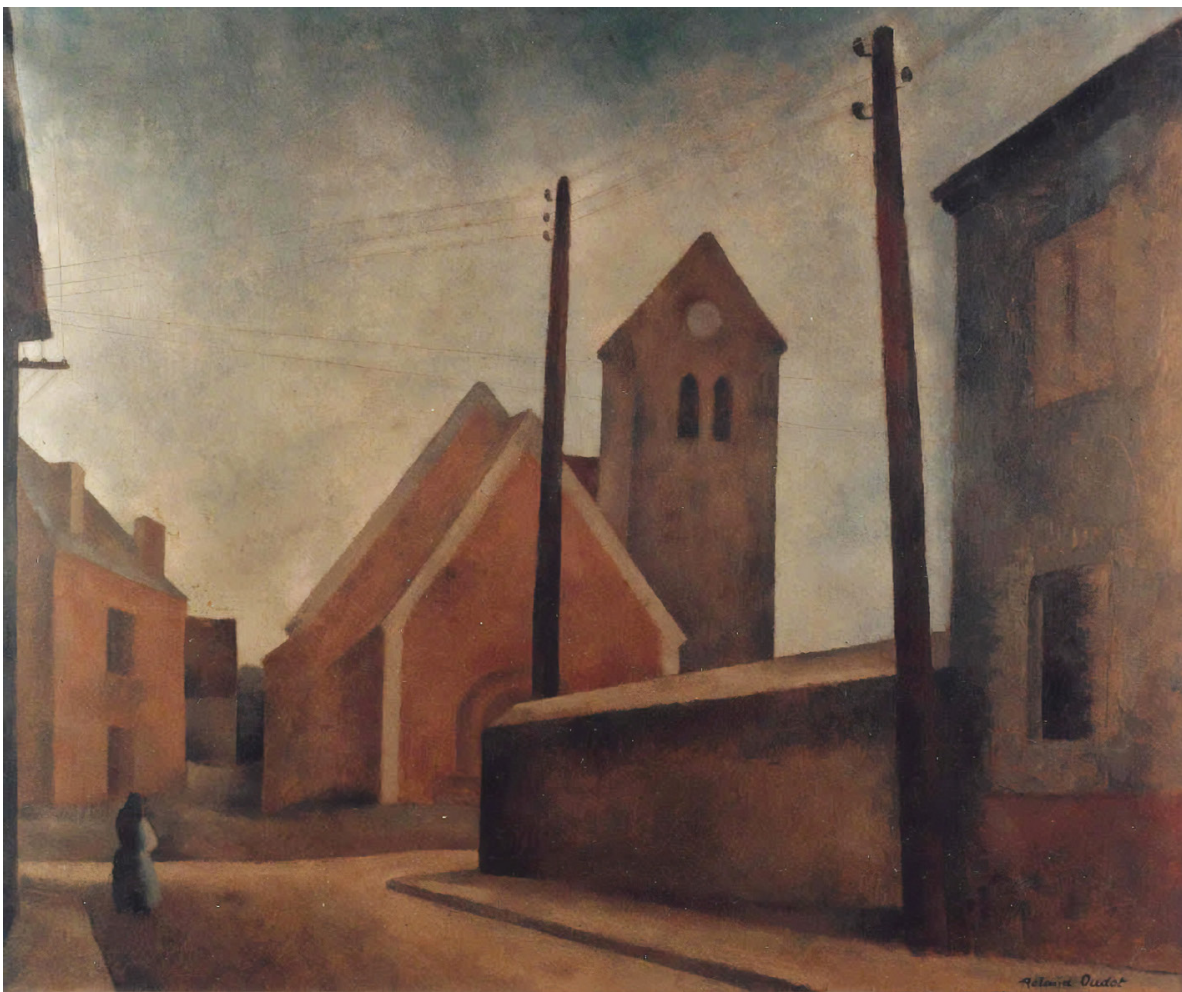

Fig. 5: Paisaje de Nozay, Roland Oudot; n.o inv. 82/315. Museo de Bellas Artes de Bilbao

24 AMBA: CD-481; 646; 641; 627; 672; 673; 647; 598; 586; 721; para una detallada reconstrucción de la colección de obras de Gauguin que poseyó Durrio ver GONZÁLEZ DE DURANA, J.: "Francisco Durrio y su colección de gauguins" en Francisco Durrio, 1868-1940 : sobre las huellas de Gauguin. Bilbao, Bilboko Arte Ederren Museoa $=$ Museo de Bellas Artes de Bilbao, 2013, pp. 195-234. 
Igualmente cabe destacar el intento de adquisición de una obra de Paul Cézanne que una comisión de la Junta de Cultura Vasca había visto en venta en París y calificó de admirable', a un precio de 95.000 francos. Como dicha suma excedía en gran medida las posibilidades económicas del museo, solicitó a la Diputación su contribución al tiempo que decidió reservar las resueltas de las consignaciones para adquisiciones de aquel ejercicio y anteriores para dicha compra, y aunque las gestiones se alargaron a lo largo de 1925, no hay más noticias al respecto ${ }^{25}$. Aduciendo razones económicas y falta de espacio, la Junta de Patronato rehusó otras ofertas que llegaron al museo a lo largo de 1924, caso de retratos de oaquín Sorolla y otras pinturas de Julio Romero de Torres y Ascencio Martiarena ${ }^{26}$. En 1925 a Junta de Patronato también recibió ofertas de Francisco Durrio para la adquisición de obras de Odilon Redon y Vincent Van Gogh, sobre las que envió fotografías y garantías de autenticidad -al parecer la obra de Van Gogh en cuestión pertenecía al pintor León GiranMax y estaba autentificada por Ambroise Vollard-, aunque nunca fueron adquiridas ${ }^{27}$. En 1929 y 1930 llegaron nuevos ofrecimientos de obras de Van Gogh, que fueron rechazadas por no representar la originalidad del artista y por su difícil autentificación ${ }^{28}$.

A pesar de concretar la intención de adquirir más ejemplos de creadores internacionales, dicho propósito no tuvo continuidad y la política de adquisiciones del Museo de Arte Moderno se centró en artistas vascos y españoles. Tal y como se ha señalado al describir la colección inaugural en el apartado anterior, entre las primeras compras realizadas por Aurelio Arteta se encontraban obras de Francisco Durrio, Ricardo Arrúe, Cristóbal Ruiz o Daniel Vázquez Díaz. En 1925 el museo adquirió distintas piezas de Joaquim Sunyer, Evaristo Valle, Juan de Aranoa, Gabriel García Maroto y Victorio Macho. Y en 1926, año en que ingresaron numerosas obras debido a la I Exposición de Artistas Vascongados y al homenaje a Iturrino, compró una nueva pintura de Vázquez Díaz.

A este último respecto merece la pena señalar el especial interés que mostró Arteta por la obra de Daniel Vázquez Díaz y de Joaquim Sunyer, quienes compartían intereses pictóricos comunes con el pintor bilbaíno, y no casualmente fueron dos de los grandes protagonistas en la recién creada colección del Museo de Arte Moderno bajo su dirección. Destacable es el caso de Vázquez Díaz (Fig. 6), quien desarrolló un proceso de simplificación que desembocaría en una estructuración formal del cubismo sin dar la espalda a la

25 AMBA: CI-D $(1924: 137 ; 139 ; 160)$

26 AMBA:CD-610;611;603; 554579 .

27 AMBA: CD-672; 598; 687; 685; 721; 4588

8 AMBA: MAM/A (3-7-1929; 29-11-1929); MAM/M (1929); MAM/A (8-8-1930); MAM/M (1930) MBA/CD-970; 997

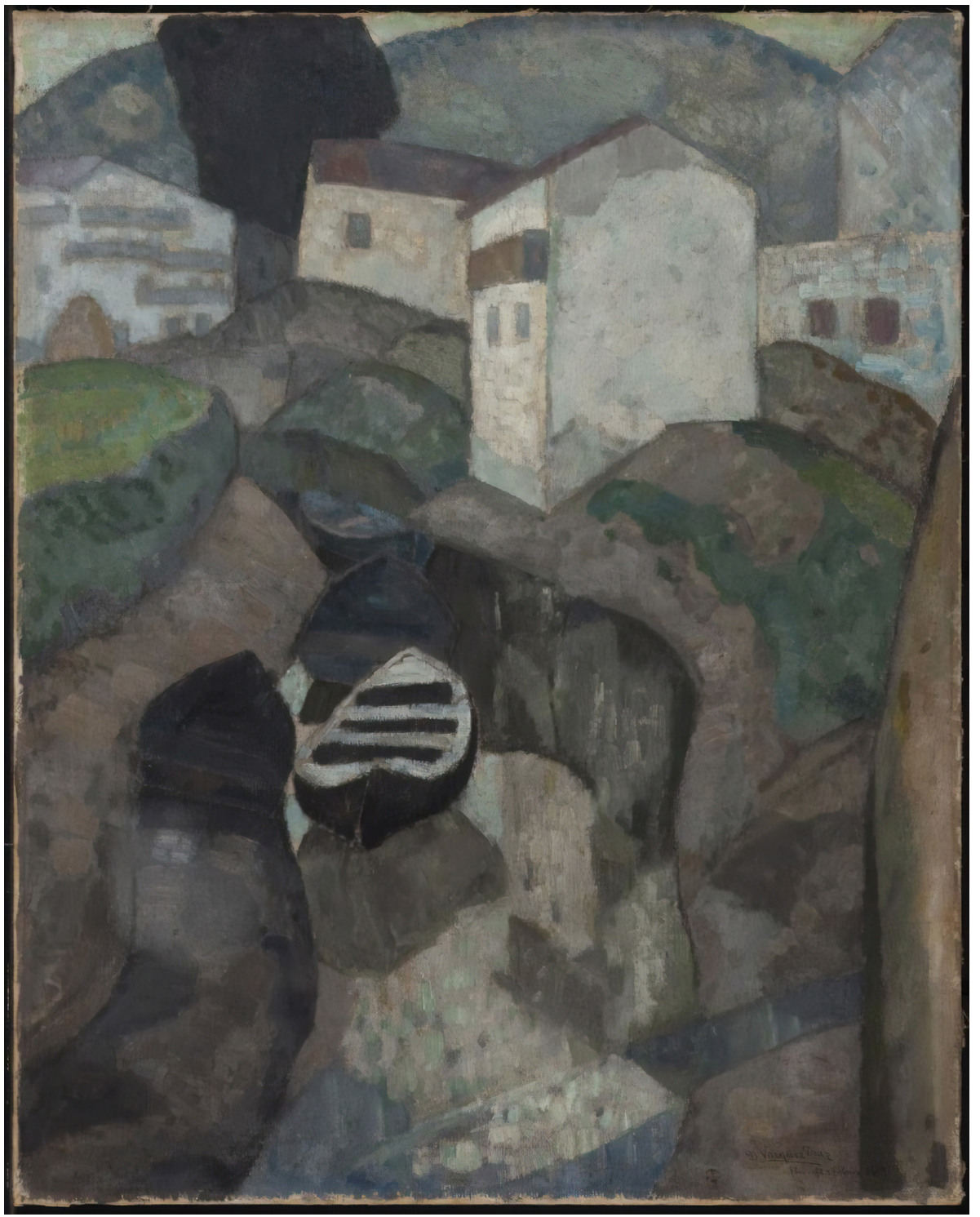

Fig. 6: Las casas del canal o La gabarra, Daniel Vázquez Díaz, 1919; n. inv. 82/381. Museo de Bellas Artes de Bilba 
representación clásica y mantuvo una estrecha relación con el País Vasco, convertida en una de las principales plataformas de difusión de su pintura a través de distintas exposicione realizadas en San Sebastián y en Bilbao -expuso en el Majestic Hall de la capital vizcaína con gran éxito en 1920 y volvió a exponer en la Asociación de Artistas Vascos en 1924 por mediación de Arteta-, y se erigió en modelo a seguir para muchos artistas locales. De hecho, la influencia del cubismo en Arteta fue colateral, fundamentalmente por influjo de Vázquez Díaz más que por asimilación directa ${ }^{29}$.

Aurelio Arteta en seguida definió una doble apuesta por adquirir conjuntamente obras de autores no consagrados en el mercado y obras de artistas de primera fila. Así, dispuesta a llevar a cabo adquisiciones más relevantes, a partir de 1926 la Junta de Patronato decidió economizar las partidas presupuestarias destinadas a tal efecto ${ }^{30}$. Sin embargo, si bien la política de ahorro tuvo éxito en el Museo de Bellas Artes con compras de interés durante aquellos años, el Museo de Arte Moderno no pudo llevar a cabo adquisiciones sonadas de algún artista de primera fila en París debido a la importante crisis que sufrió la Junta de Patronato en 1927 y a las grandes estrecheces económicas que tuvo que padecer durante los años siguientes con las rebajas de las subvenciones anuales que recibía por parte de las instituciones.

29 GONZÁLEZ DE DURANA, J. "Aurelio Arteta”, op. cit., p. 55; MANTEROLA, I.: Trama e hilos sueltos: dialogo entre dos colecciones de arte vasco. Vitoria-Gasteiz, Museo de Bellas Artes de Álava, 2014, p. 62

30 La memoria que la Junta de Patronato envió a las corporaciones patrocinadoras este año dice así a este respecto: 'Como en años anteriores ha sido la principal preocupación de la Junta de Patronato la adquisición de obras. Aunque breve la vida del Museo aconseja ya con la experiencia la táctica a seguir en las adquisiciones. Uno de los procedimientos, y que la Junta pone en cuanto puede en ejecución, es adelantarse a buscar los valores artísticos que apuntan, adquiriendo sus obras antes que alcancen cotizaciones de importancia, o, por lo menos, de importancia relativa para la consignación del Museo. Hemos logrado aś allegar a nuestra colección un número de obras de verdadero valor attístico en conder a par poder alquicir obas de artistas de ya reconocida nombrada y con cotizaciones altas, es el de hacer las máximas economías, sacrificando algunas adquisiciones del primer grupo, para poder acumular en e trascurso del tiempo la cantidad necesaria para comprar obras de primera de primeras firmas. Como e principal centro artístico es hoy París, no cabe duda de que allí es donde hay que hacer las adquisicione más importantes. Si cuando la Junta acuerda que una comision de su seno -nunca superior a dos de sus miembros y el señor director, según exigencia del reglamento- haga un viaje a París, la cantidad de dinero es de alguna importancia, puede realizar un número mayor de compras, ahorrando de ese modo los gastos accesorios de diversos viajes. Por eso este año, nos hemos limitado a dquirir exchsivamente aquellas obras que se con el ahorro realizado asi y el cobro de los últimos semestres de las Corporaciones correspondientes a 1926 y no cobradas en el curso de ese año, podrán hacerse adquisiciones importantes.'. AMBA MAM/M (1926).

\subsection{Exposiciones temporales}

Bajo el mandato de Aurelio Arteta el Museo de Arte Moderno de Bilbao puso en marcha un programa de exposiciones temporales, que no se llegó a desarrollar plenamente en sus términos iniciales. Durante su primera etapa en la dirección tuvieron lugar las dos primeras muestras, ambas en 1926 y casi simultáneamente, de las cuales el museo ingresó un número importante de obras para su colección.

En abril de 1926 se celebró una exposición homenaje a Francisco Iturrino, que llevaba gestándose desde hacía dos años, tras la muerte del pintor. Con objeto de organizar una muestra lo más completa posible, se formó una comisión compuesta por Eugenio Leal y Joaquín Zuazagoitia en representación de la Junta de Cultura Vasca de la Diputación, y Gregorio de Ybarra, Ricardo Gortázar y Aurelio Arteta en representación del Museo de Arte Moderno. En 1925 Arteta y Leal viajaron a París para gestionar el envío a Bilbao de cuadros de Iturrino, para lo cual contaron con la colaboración del sobrino del pintor Esteban Calle Iturrino.

Las obras del artista estaban esparcidas en manos diversas, lo que supuso dificultades a la hora de agrupar las cerca de 200 pinturas que se proyectaron traer, a lo que hubo que añadi las costosas gestiones llevadas a cabo en la aduana de Irún tras serles solicitados derechos por la importación de las obras. A pesar de haber sido organizada entre la Junta de Cultura Vasca y el Museo de Arte Moderno, la muestra tuvo lugar -probablemente por problemas de espacio- en las dos salas pequeñas del Museo de Bellas Artes entre el 15 de abril y el 31 de mayo, y el día de la inauguración habló el historiador del arte francés y amigo del artista Élie Faure (Fig. 7) ${ }^{31}$.

Procedentes de aquella muestra el Museo de Arte Moderno ingresó un total de 13 pinturas de Iturrino. La Junta de Patronato adquirió tres y la Diputación compró con destino al museo ocho pinturas a la familia del artista, que a su vez donó dos obras más. Con aquella importante exposición Iturrino conseguía de alguna manera la fama que durante su vida no había obtenido en Bilbao, si bien aún no contaba con una valoración significativa en el mercado, tal y como demuestran los modestos precios en los que se compraron sus obras comparativamente con otras adquiridas en la I Exposición de Artistas Vascongados.

31 AMBA. MBA/A. TII, p. 13; MBA/M (1926); MAM/M (1926); MBA/CI-D (1924: 125; 128); ADFB Educación, deportes y turismo, C-992-exp-15. 


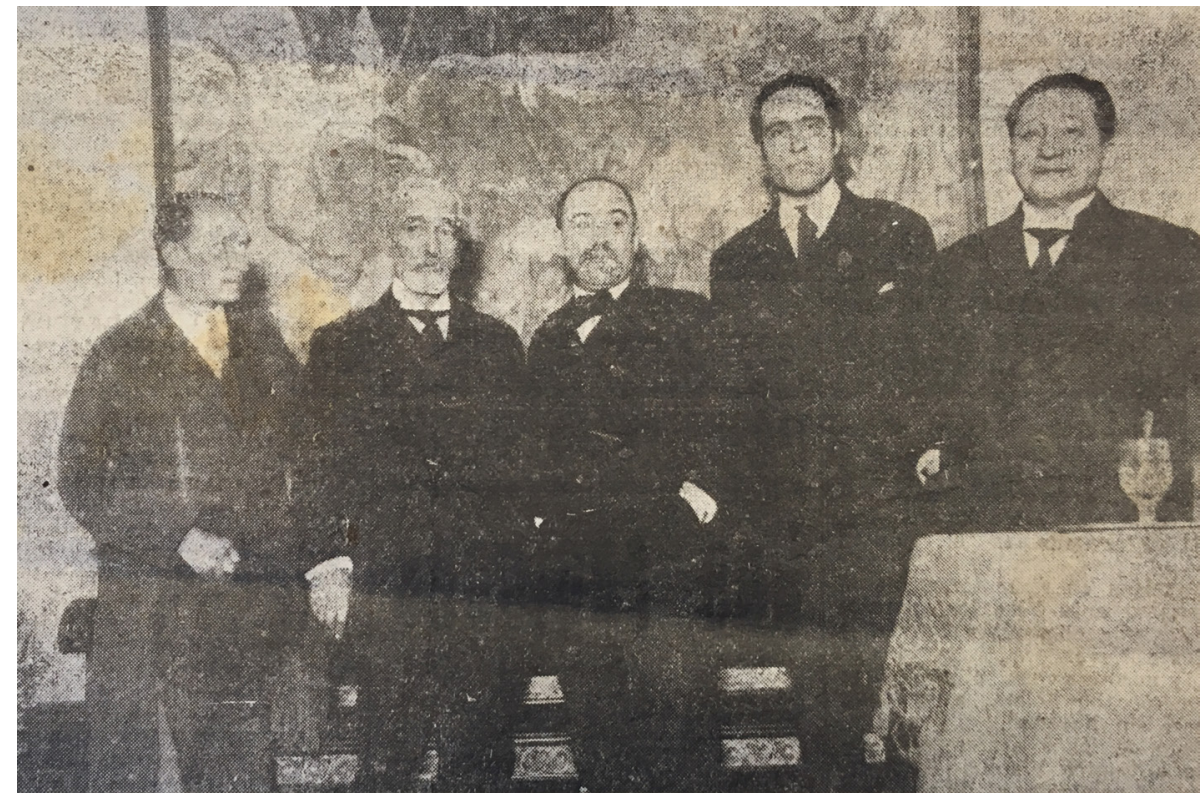

Fig. 7: Exposición-homenaje a Iturrino en el Museo de Bellas Artes de Bilbao, abril de 1926. De izquierda a derecha Aurelio Arteta, José Eugenio Baranda Icaza, Élie Faure, Pedro Mourlane Michelena y Eugenio Leal. Archivo de Museo de Bellas Artes de Bilbao

Junto con las que poseía con anterioridad del autor, el Museo de Arte Moderno había conseguido completar la sala Iturrino, cumpliendo con uno de los preceptos de su reglamento, el de lograr colecciones lo más completas posibles de los artistas del país ${ }^{32}$. Del total de las obras del pintor que posee el Museo de Bellas Artes en la actualidad las más importantes ingresaron en relación a dicha muestra. Se trata de una selección que refleja de manera bastante completa su trayectoria artística, en la que se aprecia la tendencia hacia lo exótico, la voluptuosidad del desnudo femenino y el gusto por los caballos, todo ello tratado mediante un tipo de plástica cercana a un fauvismo de corte muy personal.

32 AMBA: MBA/M (1926: 2)
A continuación, entre mayo y junio de 1926, tuvo lugar la I Exposición de Artistas Vascongados en el Museo de Arte Moderno. La muestra fue financiada por la Junta de Cultura Vasca de la Diputación con la cantidad de 15.000 ptas. como respuesta a la instancia del museo de diciembre del año anterior. La solicitud reflejaba el ánimo con que se organizaba la muestra, que justificaba como necesaria para continuar con el renacimiento artístico del país ante el pobre mercado artístico ${ }^{33}$. La Junta de Cultura Vasca delegó en la Junta de Patronato todo lo concerniente al certamen, en el que se admitieron obras de distintas disciplinas de autores vivos y el museo se reservó la selección de participantes y la elección de obras a adquirir. En una fotografía que se ha conservado de dicha muestra aparecen los principales protagonistas de la cultura artística moderna de los años 20 en Bilbao, de izquierda a derecha, Aurelio Arteta, Antonio Guezala, Gregorio de Ybarra, José Antonio Lequerica, José Eusebio Baranda Icaza, E. Bilbao, Manuel María Smith, Ornilla Joaquín Zuazagoitia, Sota, y Eugenio Leal. Al fondo, entre otros, se puede ver el cuadro de Jesús Olasagasti Las hermanas (1926; n. ${ }^{\circ}$ inv. 82/167), adquirido por el museo en dicha muestra (Fig. 8).

33 El texto presentado ante la Junta de Cultura Vasca dice así: 'Tanto por el espíritu que informaba de motivación por la cual este Museo fue creado como por el Reglamento que nos rige, estamos obligados a adquirir las colecciones más completas posibles de los artistas del País que merezcan esa consideración. En el deseo de cumplimentar este deber y de acuerdo también con lo previsto en el mismo reglamento, hemos pensado que ha llegado el momento oportuno de organizar exposiciones anuales de artistas del país -que de tener éxito podrían convertirse en nacionales- no solamente para poder adquirir aś las obras mejores con más probbilidades de acierto sino para fomentar el desenvolvimiento Thir as las obras mejo con que ha desbordado los límites comarcanos para conseguir una aquiescencia nacional verdaderament honrosa. Sin embargo, este selecto plantel de artistas no produce ni en cantidad ni en calidad las obras que debiera producir, y ello es debido, sin género de duda, a que el mercado artístico es mezquinísimo. Nadie compra obras que por su importancia sobrepasen a los modestísimos precios que las gentes están habituados a pagar. Cohibidos así los artistas no se lanzan a empresas que serían infructuosas. Limítanse a producir obras que puedan ser fácilmente adquiridas y que les permita ir viviendo aunque sea malamente. Urge, pues, si no queremos que el renacimiento artístico de Vizcaya se malogre, prestarle algún apoyo oficial. Por el momento no encontramos mejor procedimiento que el de la organizaćn mejores' AMB : Inso enviada a la Junta de Cultura Vasca; EAV (1926); CI-D (1925; 162; 163); ADFB: Educación, deportes y turismo, C-992-exp-13. 


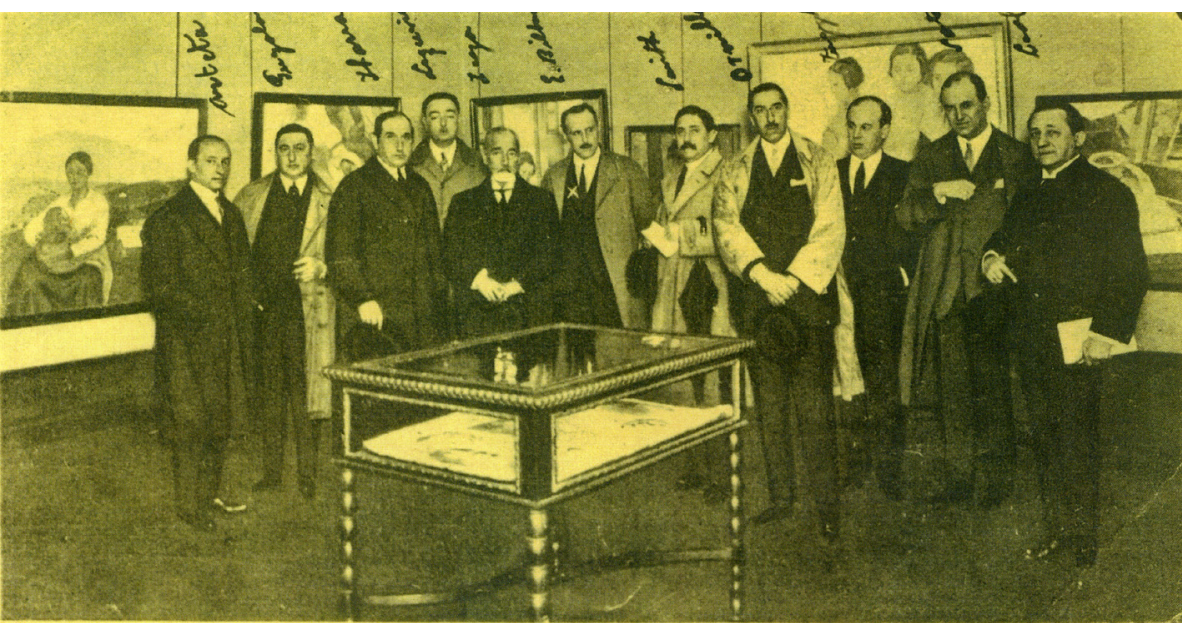

Fig. 8: I Exposición de Artistas Vascongados en el Museo de Arte Moderno de Bilbao. Archivo del Museo de Bellas Artes de Bilbao

Participaron 42 artistas con 99 obras, casi todos ellos jóvenes creadores como Jenaro Urrutia, Ernesto Pérez Orúe, José Benito Bikandi, Jesús Olasagasti, Gaspar Montes Iturrioz, Asunción Asarta o Juan de Aranoa, junto a otros pocos veteranos como Manuel Losada, Julián de Tellaeche o Gustavo de Maeztu ${ }^{34}$. El Museo de Arte Moderno adquirió ocho obras en total, seis pinturas y dos esmaltes, de Jesús Olasagasti, José Benito Bikandi, Ernesto Pérez Orúe, Ramiro y Ricardo Arrúe, Juan de Aranoa y Jenaro Urrutia. Se trata de un grupo de obras de cierto interés entre las que encontramos artistas que ya estaban representados en el museo así como dos nuevos creadores con sendas pinturas destacables, un delicado desnudo del bilbaíno Pérez Orúe y una bella escena de Olasagasti, que había estudiado con Daniel Vázquez Díaz y entonces solamente contaba con dieciocho años, que remite al cubismo atemperado típico de los artistas vascos de su época ${ }^{35}$

34 Exposición de Artistas Vascongados. (Bilbao : Museo de Arte Moderno de Bilbao), 1926; ABDF: Educación, deportes y turismo, C-992-exp-13.

35 Guía Artistas Vascos. Museo de Bellas Artes de Bilbao. Bilbao, Museo de Bellas Artes de Bilbao, 2008, pp. 116-117.
La Junta del Museo de Arte Moderno, que consideró esta primera exposición como un ensayo modesto de un plan más amplio, calificó la muestra de exitosa, si bien resultó más interesante la novedad de la iniciativa en sí que el resultado final, que fue acogida por la crítica sin demasiado entusiasmo ${ }^{36}$. Del mismo modo es de subrayar que en la misma no se llevaron a cabo todas las compras posibles y que sobraron casi 8.000 pesetas que no se invirtieron en la adquisición de más obras, debido a que la Junta procuró limitar el número de adquisiciones solamente a las que realmente tuvieran verdadero valor estético, y además, solicitó a los pintores rebajas considerables en los precios, que aquellos al parecer $\operatorname{aceptaron}^{37}$

A través de la organización de la Exposición de Artistas Vascongados el Museo de Arte Moderno continuaba con la apuesta por la adquisición de jóvenes valores que la Junta de Cultura de la Diputación Provincial había iniciado poco antes de la creación del museo, cuando en la Exposición de Bellas Artes del III Congreso de Estudios Vascos de Gernika celebrado en septiembre de 1922 compró, junto a obras de artistas con cierta trayectoria como Manuel Losada, Julián de Tellaeche o Benito Barrueta, ejemplos de artistas muy jóvenes como José María Ucelay, Asunción Asarta, José Benito Bikandi, Juan José Landa, Ernesto Pérez Orúe o Jenaro Urrutia, todas ellas con destino al Museo de Bellas Artes en ese momento, y al Museo de Arte Moderno en $1924^{38}$.

\section{POLÉMICA Y DIMISIÓN}

Coincidiendo con uno de los mejores momentos del Museo de Bellas Artes, que gestionaba la adquisición de un retrato de Felipe IV atribuido a Velázquez y el legado de la gran colección de Laureano de Jado, en 1927 el Museo de Arte Moderno vivió una importante

36 A este respecto destaca la crítica de Crisanto Lasterra, quien tras aplaudir la iniciativa, lamentaba que muestra no hubiera resultado tan brillante como hubiera sido deseable, fundamentalmente a causa de la pobre calidad de la producción artística del momento. LASTERRA, C.: "Notas de Arte. La Exposición de Artistas Vascos". Euzkadi, Bilbao, 23/05/1926. Recogido en Novecentismo y Vanguardia (1910-1936) en la colección del Museo de Bellas Artes de Bilbao. Bilbao, Museo de Bellas Artes de Bilbao, 2009, pp. 462-463. Selección de Miriam Alzuri.

37 AMBA: MAM/M (1926: 3); EAV (1926).

38 Catálogo Exposición de Arte. III Congreso de Estudios Vascos. Gernika. Septiembre 1922, Excma. Diputación de Vizcaya, Imprenta moderna Medinabeitia y Zallo, Gernika, 1922; MOYA, A. "Tradición y modernidad. Arte y artistas vascos en el Museo de Bellas Artes y Arte Moderno de Bilbao", Bidebarrieta. Revista de humanidades y ciencias sociales de Bilbao, n. ${ }^{\circ}$, II Symposium de Bilbao 700 años de memoria. Arte, Patrimonio monumental y ciudad, 1997, p. 102. 
crisis que derivó en una polémica que alcanzó repercusión a nivel estatal. La falta de sensibilidad y comprensión de la clase política hacia su orientación artística tuvo como consecuencia la dimisión de Aurelio Arteta y de una parte de su Junta de Patronato.

En el debate sobre el presupuesto anual del Ayuntamiento de Bilbao celebrado el 1 de febrero de 1927 surgió una discusión referente a la financiación del Museo de Arte Moderno. Mientras algunos concejales defendieron reducir la partida presupuestaria, otros, con el Alcalde Federico Moyúa al frente, apostaron por la fusión del Museo de Bellas Artes y el Museo de Arte Moderno en una única institución, con el argumento de que supondría un significativo ahorro en personal y materiales ${ }^{39}$. Si bien la propuesta de fusión de los museos no sería aprobada hasta abril, en dicha sesión el Ayuntamiento acordó una reducción de la subvención para años posteriores ${ }^{40}$, aunque el aspecto más polémico resultaron las manifestaciones de varios miembros de la corporación. Tal y como recogió la prensa de aquellos días, en el pleno se defendió que con la fusión y el ahorro de las 11.685 ptas. que se invertían en personal podrían adquirirse obras de mérito pictórico que avalasen el museo. Es más, el Teniente de Alcalde Daniel J. de Aresti afirmó que el Museo de Arte Moderno solo servía para proporcionar colocación a señores que no tenían grandes ocupaciones y que algunas obras del mismo pertenecían a pintores que no tenían mercado más allá de las fronteras de la provincia. Por su parte, el Alcalde llegó a comentar que era posible que ni regaladas aceptara aquellas obras ${ }^{41}$

Enterado por la prensa de que varios concejales y el Alcalde habían exteriorizado el manifiesto disgusto que les causaba la orientación del museo, Aurelio Arteta se sintió desautorizado públicamente y presentó su dimisión como director el 3 de febrero. En la carta enviada a la Junta de Patronato manifestó que no podía, en conciencia, seguir contribuyendo a sostener un criterio que tales ascos y desdenes causaba, y mucho menos impedir o dificultar con

39 ABDF: Educación, deportes y turismo, C-993-exp-24.

Tanto el Ayuntamiento como la Diputación redujeron las consignaciones anuales al Museo de Arte Moderno en 1927 , de 15.000 a 11.250 ptas. el primero, y de 20.000 a 15.000 ptas. el segundo. La Diputación explicó la reducción por la revisión que estaba llevando a cabo de las subvenciones que prestaba a varias instituciones de carácter cultural para acomodar dichas aportaciones al nuevo Concierto Económico. En cambio, la reducción de la consignación por parte del Ayuntamiento tenía causas más relacionadas con la valoración del propio Museo de Arte Moderno por parte de la corporación municipal. Cualque-

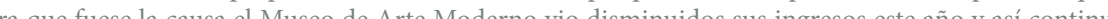
a continuó por pas las por parte de las dos instituciones. AMBA: MAM CI-A (1928: 99)

41 Euzkadi, 02/02/1927; El Noticiero Bilbaíno, 10/02/1927; MUR, P. “La Asociación de...”, op. cit., p. 116. el sueldo que venía disfrutando la adquisición de obras mejores ${ }^{42}$. Ante tal situación, el 7 de febrero los vocales vecinos nombrados por el Ayuntamiento -Alejandro de la Sota Ricardo Gortázar, Gregorio de Ybarra y Joaquín Zuazagoitia- presentaron igualmente su dimisión explicando que las críticas del consistorio hacia el museo no sólo fueron hacia su orientación artística, sino a la gestión de la Junta, y del mismo modo destacaron la ejemplaridad extraordinaria del director dimisionario al frente del museo, mostrando su agradecimiento a los concejales que los apoyaron con su voto ${ }^{43}$. Aquellos acontecimientos provocaron una polémica pública en la que participaron José Félix de Lequerica, quien desde la prensa censuró la actuación del Ayuntamiento y la política cultural estatal, el propio Alcalde, que se sintió aludido ante las acusaciones de 'chamorrismo', y la Asociación de Artistas Vascos, la cual se manifestó a favor de la existencia de los dos museos y defendió la labor de Arteta al frente del Museo de Arte Moderno ${ }^{44}$

El apoyo al director dimisionario se plasmó en un banquete-homenaje celebrado el 12 de febrero en el Hotel Carlton, que reunió a más de un centenar de comensales -entre ellos varios creadores como Quintín de Torre, Jenaro Urrutia, Julián de Tellaeche, José María Ucelay, Antonio Guezala o Gustavo de Maeztu y personalidades de la cultura y la política como Gregorio de Ybarra, Estanislao María de Aguirre, Alejandro de la Sota o José Félix de Lequerica- y contó con innumerables muestras de solidaridad de artistas e intelectuales españoles, lo que ha sido considerado como una contestación desde el ámbito artístico a la dictadura de Primo de Rivera (Fig. 9) ${ }^{45}$. Distintos oradores como Pedro Mourlane Michelena y Joaquín de Zuazagotia pronunciaron discursos que fueron reproducidos en la prensa y también se leyeron distintas adhesiones al homenaje ${ }^{46}$. Numerosas personalidades

42 AMBA: MBA/CD-822

43 La carta de los vocales dimisionarios dice así: 'La orientación artística del museo, es de competencia exclusiva de su Junta de Patronato, que en todo momento ha seguido las normas que le imponía su criterio estético, en el cual nos mantenemos, y que, por otra parte, coinciden con la orientación que señala el reglamento del museo. Este criterio y esta orientación, como todo, están sujetos a disputa y, por tanto, nada nos extraña y menos ofende, el que se les combata con apreciaciones demasiado fáciles de prever Lo que no podemos dejar sin protesta es el que se involucrara todo esto con la gestión de la Junta en lo referente a personal y adquisiciones, haciéndola parecer fácilmente inclinada a los favores amistosos. Las apreciaciones a que nos venimos refiriendo, revelan por otra parte, un absoluto desconocimiento del asunto, como puede comprobarse con solo leer las memorias que la Junta ha presentado anualmente a las corporaciones.' AMBA: Carta. Donación Magdalena Gortázar

44 José Félix de Lequerica. "Una enfermedad nacional. El chamorrismo" El Pueblo Vasco, 06/02/1927; "Una carta de la Asociación de Artistas Vascos" El Pueblo Vasco, 10/02/1927; MUR, P. "La Asociación de..., op. cit., p. 118-119.

45 KORTADI, E.: op. cit., p. 62

46 "Anoche en el Carlton. El Homenaje a Aurelio Arteta constituyó un acto magnífico". El Liberal, 13 /02/1927, 


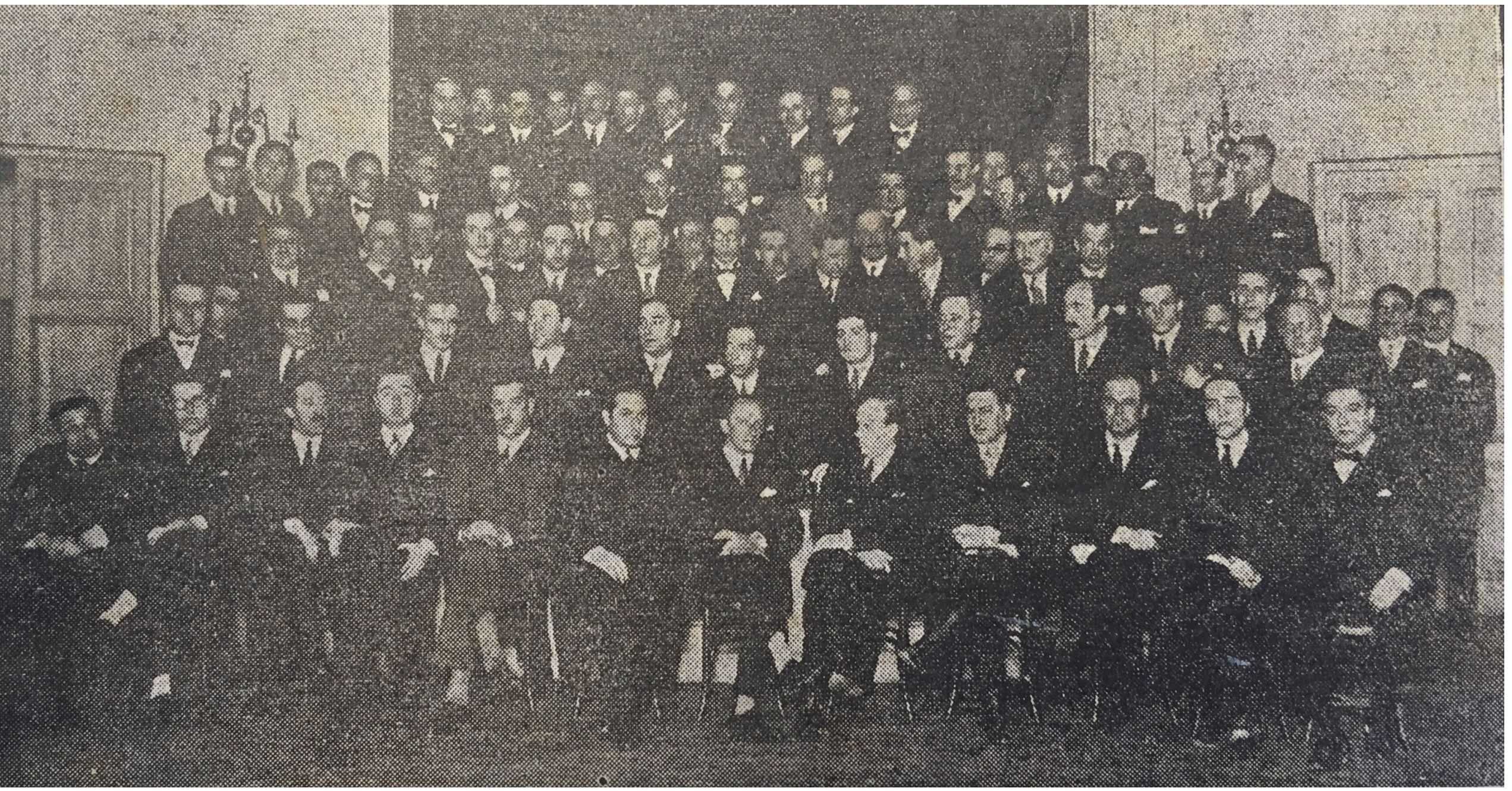

Fig. 9: Homenaje a Aurelio Arteta en el Hotel Carlton de Bilbao. El Noticiero Bilbaíno, 13/02/1927 
del mundo de la política, la industria y la cultura escribieron a Arteta mostrando su apoyo, muchos de ellos excusando su ausencia en el banquete, entre ellos Lorenzo Hurtado de Saracho, Ramón de Basterra, Antonio Plasencia, Moisés de Huerta, Ricardo Bastida, Julio Beobide, Ramón de la Sota y Aburto, Manuel María Smith, Damián Roda, Ramiro y Alberto Arrúe, Ignacio Zuloaga, Manuel Azaña, Ricardo y Pío Baroja, Ramón Góme de la Serna, Juan Ramón Jiménez, Federico García Lorca, Juan de Echevarría, Margarita Nelken, Rafael Alberti, José Ortega y Gasset, Gregorio Marañón y otros muchos ${ }^{47}$. Entre las mismas cabe destacar el apoyo de Juan de la Encina, convaleciente en Madrid debido a un accidente doméstico, que se hizo eco de la dimisión de Arteta en las páginas de La Voz Y envió al acto de desagravio al pintor una nota de adhesión con una dura crítica a la política cultural española ${ }^{48}$

Paradójicamente, en un intento de sumarse al mismo, el Alcalde y el Teniente de Alcalde de Ayuntamiento de Bilbao participaron en el homenaje, al que enviaron un escrito publicado en la prensa el día siguiente donde manifestaban su simpatía y admiración hacia Arteta pero mantenían la idea de reorganizar la estructura del museo arguyendo razones económicas. Solicitaban que sus juicios fueran tan respetados como los de quienes imponían el criterio dominante en el Museo de Arte Moderno, citando para ello un artículo publicado aquellos días por el crítico francés Léon Werth en el periódico madrileño El Sol bajo el título 'El 'volakup' pictórico's9. Se conserva la respuesta, fechada el 16 de febrero, que dirigió a los mismos Aurelio Arteta, en la que defiende su gestión y se reafirma en su dimisión. Dejando de lado todo supuesto agravio hacia su persona y sus méritos como artista, el pintor bilbaíno justificaba su gestión en la dirección, especialmente las adquisiciones llevadas a cabo

p. 3; "Un homenaje a Aurelio Arteta: el Ayuntamiento y el Museo de Pintura Moderna de Bilbao". La Esfera: Ilustración Mundial, Madrid: Prensa Gráfica, no 686 (26/02/1927) p.7.

47 AMBA: Carpeta Aurelio Arteta, AA36-AA77.

48 La carta enviada por Juan de la Encina a Arteta y leída en el Hotel Carlton dice así: "El 'chamorrismo que ha definido de modo insuperable nuestro José Félix de Lequerica, le ha vencido a usted. Ha vencido antes a otros más fuertes. Nos vencerá; si no ha vencido ya hace tiempo, yo así lo creo a veces, a todos los españoles empeñados en la empresa de vivir según el espíritu. La Beocia, y su expresión más vil, e 'chamorrismo' no es sólo de nuestro pueblo; es de toda la Península, como ha observado tan finamente su último definidor -el primero fue Goya-. Una tromba repugnante de plebeyez y chocarrería parece como que quisiera apagar hasta el último destello de espiritualidad nacional. No en el candelabro, para el que se hizo sino bajo el almuz es donde se pretende poner para que no alumbre la antorcha Por lo

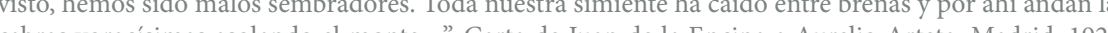
cabras voracisinas asolano el 1927 Febrero. AMBA. Carpeta Aurelio Arteta, AA53; ALZURI, M. Juan de la Encina: una trama para el art vasco. Bilbao, Muelle de Uribitarte Editores, 2013, p. 79

49 ADFB: Bilbao Undecima 0127/276; La Gaceta del Norte. 13/02/1927. -afirmando incluso que se arrepentía de no haber propuesto a la Junta la compra de obras importantes por tratarse de artistas amigos suyos-, defendía su criterio artístico y el de los miembros de la Junta, y achacaba la mala situación económica del museo no a los gastos fijos que suponía, sino a la reducción de su ya de por sí escasa consignación ordinaria ${ }^{50}$.

50 La carta de Arteta dice asía aste respecto: '(N)o se trata en este caso de la conducta del hombre ni de los méritos del pintor. Se trata, ustedes lo saben muy bien, del criterio artístico que ha representado en el Museo de Arte Moderno de Bilbao su director, y, también, aunque un poco vagamente, de su conducta respecto a las adquisiciones.

Estaría yo completamente tranquilo por ese lado, si no hubiera caído en el pecado que ya confesé, de no haberme atrevido a proponer a la Junta adquisiciones de obras meritísimas de artistas bilbaínos, por ser sus autores amigos entrañables míos.

Pero, superando éste pesar estoy por lo demás, absolutamente satisfecho de mi gestión. Las adquisi-

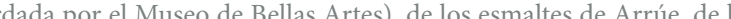
escultura de Macho, de los cuadros de Aranoa, Cristobal Ruiz, Evaristo Valle, Maroto, Sunver, Iturrino y Vázquez Díaz, y las de los extranjeros Antral, Oudot, Jéan Berque y Zak, satisfacen plenamente mi orgullo y creo que no me arrepentiré nunca de ellas.

En cuanto a que les sea a ustedes permitido considerar administrativamente la organización del Museo no hay que hablar; es además, un deber de sus altos cargos. Que las cifras de los gastos fijos asciendan este año, después de la reducción de las subvenciones a un 54,80 por los de la consignación total, según las cuentas minuciosas de ustedes, no me extraña nada. Todo depende de la cantidad de las consignaciones y en este aspecto de la cuestión de la de haber presentado la dimisión de mi cargo para no contribuir con el sueldo que disfrutaba al posible, por lo vesto, desequilibrio del erario municipal, no tengo nada que añadir

Pero he de discrepar de la opinión muy respetable de ustedes, en cuanto a que sus juicios artísticos 'sea tan respetuosos como los de quienes imponen el criterio dominante en el Museo de Arte Moderno: Eso no: el criterio dominante en el Museo de Arte Moderno ha sido el mío. Los señores que conmigo han compartido la labor son para mí de absoluta solvencia artística; pintores unos, otro crítico, coleccionista otro, aficionados competentísimos de siempre los demás y depurados y exigentes catadores de pintura todos, eran para mí una garantía. Ellos, con su entusiasmo y su esfuerzo de muchos años

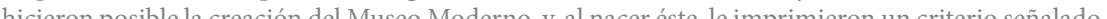
el preámbulo de su reglamento, con e aceptado el cargo.

No puedo, pues, repartir por igual mi respeto a un criterio que comparto y que -con todos los riesgo posibles de equivocarme- me parece, naturalmente, el mejor, y otro que, según Vdes. mismos declaran, no tienen. Pero, si para tener alguno se apoyan ustedes en el del prestigiosísimo crítico Leon Werth -en cuya admiración coincidimos pero cuyas apreciaciones en el artículo a que Vdes. hacen referencia, no pueden, a mi juicio, alcanzar a nuestro Museo- debieran, dicho con todo respeto, haberse abstenido de juzgar, hasta que dicho señor, les dictara el fallo.

Y como no he visto en la carta de Vdes, -por otro lado tan amable- la menor palabra acerca de mi gesYcono no hevisto en molesta de suponerme falto de criterio propio o en caso de tenerlo sometido al de los demás, me afirmo ahora, con más motivos todavía, en la actitud que tomé desde el primer momento presentando $\mathrm{m}$ dimisión. AMBA: Carta. Donación Magdalena Gortázar. 
La dimisión de Arteta y de los miembros de la Junta fue aceptada por el Ayuntamiento y la corporación municipal nombró en sustitución de los cuatro dimisionarios tres nuevos vocales vecinos, Antonio Guezala -vocal hasta entonces por parte de la Diputación-, Manuel María Smith y Nilo Ortiz de Landa, participantes también en la Junta del Museo de Bellas Artes ${ }^{51}$. En sesión celebrada el 20 de abril, el Ayuntamiento aprobó la propuesta de fusión de los museos bajo la Junta de Patronato del Museo de Bellas Artes. Sin embargo, el acuerdo, que se tomó en base a un informe en el que se expresaba la opinión del Alcalde Moyúa de que la dimisión del director del Museo de Arte Moderno Aurelio Arteta facilitaría la operación, no fue aceptado por la Diputación y la fusión no se llevó a cabo ${ }^{52}$.

La nueva Junta de Patronato del Museo de Arte Moderno designó con carácter interino a Manuel Losada como nuevo director, quien tomó posesión del cargo el 8 de noviembre de 1927, y ocupó ese puesto hasta el nuevo nombramiento de Arteta y de los vocales vecinos dimisionarios en 1931. Losada continuó, esencialmente, la misma senda marcada por Arteta durante los años en los que la dirección estuvo en sus manos, si bien sus posibilidades económicas se vieron afectadas y la actividad de la Junta se vio ralentizada ${ }^{53}$. A partir de 1928 el Museo de Arte Moderno llevó a cabo adquisiciones de obras de artistas como Ascensio Martiarena, Mateo Inurria, José Gutiérrez Solana, Julián de Tellaeche y Gustavo de Maeztu, parte de ellas comprometidas por la Junta de Patronato anterior. En 1929 se compraron algunas esculturas de Francisco Durrio, y en 1930 dos pinturas de Gerardo de Alvear y Joaquim Sunyer.

\section{RETORNO A LA DIRECCIÓN. LA DÉCADA DE LOS AÑOS 30}

Tras su dimisión Arteta se refugió en la costa vasca, retomó las escenas de género marinero y resolvió su vida económica con la realización de retratos de personajes y familias del Bilbao acaudalado. Entre 1928 y 1929 realizó, con numerosos problemas por parte del obispado local, los frescos del seminario de Logroño. Desde el punto de vista pictórico, durante finales de la década de los años 20 y primeros 30 Arteta desarrolló un tipo de obra derivada de la síntesis cubista mediante la que trató temas comerciales como aldeanos, pescadores y jóvenes de tímido gesto y bellos rostros situados en entornos cercanos, y perfeccionó su técnica del óleo, hasta lograr carnosidades y volúmenes de enorme calidez mediante la degradación de luces y colores. Al mismo tiempo, obtuvo cierto

51 AMBA: MAM/A (8-10-1927); CI-A (1927: 94; 95; 96; 97).

ADFB: Educación, deportes y turismo, C-933-exp-24, Bilbao Undécima 0127/276.

53 AMBA: MAM/A (8-10-1927); (10-2-1928); CI-D (1927: 186); CD-813; 814; 815; 816 reconocimiento institucional al ser galardonado con el Premio Nacional de Pintura en 1930 con la obra Las bañistas, una escena que aborda el desnudo femenino desde postulados post-cezanianos, y con una Primera Medalla en la Exposición Nacional de Bellas Artes en 1932 con la composición de carácter existencialista Los náufragos, tema sobre el que volvió en numerosas ocasiones a lo largo de los años ${ }^{54}$.

El cambio político que tuvo lugar en España en 1931 con el advenimiento de la República tuvo cierta repercusión en la situación cultural y artística del país, y Arteta no fue ajeno a la misma. El 5 de agosto de ese año fue de nuevo nombrado director del Museo de Arte Moderno de Bilbao, recuperando su puesto junto a los vocales vecinos dimisionarios. Debido a razones de salud Arteta no se hizo cargo de la dirección de manera inmediata aunque tal y como se deduce de la correspondencia de la época, se incorporó antes de acabar el año, de modo que a finales de 1931 la nueva Junta de Patronato y la dirección estaba fundamentalmente integrada por los que habían sido impulsores y creadores de museo diez años antes ${ }^{55}$

Con el restablecimiento de Arteta y de la Junta de Patronato, que empezó su nueva etapa decididamente a pesar de los problemas de espacio y de la escasez económica, el Museo de Arte Moderno vivió un pequeño resurgir. Si bien no se guardan las actas de las reuniones de la Junta de Patronato, de la consulta de otras fuentes se deduce la intención de retomar su actividad inaugural. En noviembre de 1931 acordó celebrar la segunda edición de la Exposición de Artistas Vascongados y en diciembre llevó a cabo adquisiciones de pinturas de Alberto Arrúe, Juan de Echevarría y Francisco Iturrino ${ }^{56}$.

Durante los años siguientes la nueva Junta de Patronato organizó dos nuevas ediciones de la Exposición de Artistas Vascongados, que tuvieron lugar en el museo en 1932 y 1934. A pesar de que la Asociación de Artistas Vascos, que vivía una época de dificultades económicas, continuaba con su programa de exposiciones colectivas e individuales, los años 30 resultaron una época difícil para las artes plásticas, y en ese sentido la II y III Exposición de Artistas Vascongados han sido consideradas como una excepción en una época en el que el ímpetu con el que Bilbao había mantenido la antorcha de la modernidad estaba en horas bajas y San Sebastián se erigió en referencia cultural y artística en el País

54 GONZÁLEZ DE DURANA, J.: "Aurelio Arteta", op. cit., p. 93

55 AMBA: MAM/A (5-8-1931); MAM/M (1931: 1-2); CD-821 (parte trasera); 1112; 1231

56 AMBA: MAM/M (1931:2). 
Vasco en detrimento de la capital vizcaína ${ }^{57}$. La segunda edición de la Exposición de Artistas Vascongados, celebrada entre mayo y junio de 1932, continuó el espíritu de la primera y expuso 119 piezas de 66 artistas procedentes de las cuatro provincias. El Museo de Arte Moderno ingresó varias obras para su colección y la exposición supuso la confirmación de la generación de los años 20 -Jenaro Urrutia, Juan de Aranoa, Jesús Olasagasti- junto a artistas consagrados como los hermanos Arrúe, los Zubiaurre, Julián de Tellaeche y Gustavo de Maeztu ${ }^{58}$. Por su parte, la III Exposición de Artistas Vascongados tuvo lugar en diciembre de 1934 y acogió 124 obras de 68 artistas, gran parte de ellos participante en la edición anterior, muchos miembros de la Asociación de Artistas Vascos y también de la recién creada Asociación Unión Arte. Cabe destacar la presencia de José María de Ucelay -ausente en las dos primeras ediciones- y de un joven Nicolás Lekuona, así como la ausencia de Jesús Olasagasti. En su última edición el Museo de Arte Moderno ingresó para sus fondos obras de autores jóvenes y, aunque sin despertar demasiada expectación, resultó una muestra referente para los nuevos creadores que querían hacerse un hueco en el sistema artístico ${ }^{59}$.

Sin embargo, la segunda etapa de Aurelio Arteta como director del Museo de Arte Moderno fue también muy breve, pues atraído por la política artística del nuevo régimen con el que colaboró activamente y donde muchos de sus amigos ocupaban puestos de responsabilidad -Juan de la Encina, nuevo director del Museo de Arte Moderno de Madrid, incorporó a Arteta al Consejo de Cultura- $-^{60}$, en seguida se trasladó a la capital española y en 1933 fue nombrado interinamente profesor de la Escuela de Bellas Artes de San Fernando. La Junta de Patronato del Museo de Arte Moderno acordó concederle permiso para que pudiera cumplir tan 'honroso' cometido, ante lo cual Manuel Losada de nuevo tomó las riendas de la dirección ${ }^{61}$. Arteta solicitó el permiso con objeto de realizar unas oposiciones que debían tener lugar en tres meses, aunque su celebración se retrasó y en años siguientes tuvo que solicitar el aplazamiento de su excedencia en distintas ocasiones, dado que estaba convencido que de aquel modo obtendría una mayor estabilidad laboral y económica que en su puesto en el Museo de Arte Moderno de Bilbao, cuyo escaso apoyo por parte de las

57 MUR, P.: "Después de la edad de la inocencia", en Novecentismo y Vanguardia (1910-1936) en la colección del Museo de Bellas Artes de Bilbao. Bilbao, Museo de Bellas Artes de Bilbao, 2009, p. 31.

58 Segunda Exposición de Artistas Vascongados. (Bilbao, Museo de Arte Moderno de Bilbao, 1932); AMBA: MAM/M (1932: 1-2): MBA/EAV (1932).

59 Tercera Exposición de Artistas Vascongados. (Bilbao, Museo de Arte Moderno de Bilbao), 1932; ADFB Artes, C-1203-exp-4

60 FERNÁNDEZ DE LA SOTA, J.: Aurelio Arteta: los trabajos y los días. Bilbao, Muelle de Uribitarte, 2015, p. 113.

61 AMBA: MAM/M (1933: 1); MBA/CD-1241; 1253 instituciones ahondaron el desencanto que Arteta venía arrastrando desde su dimisión en $1927^{62}$. A pesar de su marcha, el Museo de Arte Moderno de Bilbao continuó en constante relación con el pintor bilbaíno con objeto de mantenerse informado sobre los nuevos valores que destacaban en la capital española y cuya obra pudiera tener interés para sus colecciones, medio por el que llegaron diversos ofrecimientos ${ }^{63}$.

A lo largo de la década de los años 30, a pesar de su delicada situación económica, el Museo de Arte Moderno llevó a cabo adquisiciones destacadas. Además de obras procedentes de las citadas Exposiciones de Artistas Vascongados de artistas locales veteranos y otros más jóvenes que despuntaron en la década de los años 20 y llegarían a formar el núcleo de la nueva generación de creadores del país, también se llevaron a cabo compras directamente a artistas o a coleccionistas particulares. Llegaron a la colección esculturas de Francisco Durrio y nuevas pinturas de Darío de Regoyos, Gustavo de Maeztu, Ángel Larroque, Quintín de Torre, los hermanos Arrúe, Manuel Losada o Juan de Aranoa. Igualmente recibió algunas donaciones en relación a las compras, así como otras como dos litografías de Cézanne que habían sido expuestas en la I Exposición de Pintura y Escultura de 1919 -Les petits baigneurs (Pequeños bañistas) (1897; $\mathrm{n}^{\circ}$ inv. 82/368) y Les grands baigneurs (Grandes bañistas) (c. 1898; n. ${ }^{\circ}$ inv. 82/369)- y habían pasado por distintas colecciones particulares, donadas por Joaquín Zuazagoitia.

En 1936 el Museo de Arte Moderno adquirió dos significativas pinturas de Aurelio Arteta de quien el año anterior había ingresado su composición Paisaje urbano con figuras o Barrio obrero (c. 1919; n. ${ }^{\circ}$ inv. 82/160) como donativo por parte de Antonio Plasencia. Las citadas compras, realizadas en abril de 1936, corresponden a Layadores o Idilio rústico (n..$^{\circ}$ inv. 82/157) (Fig. 10) y Pescadores vascos (n. ${ }^{\circ}$ inv. 82/155), dos buenos ejemplos de la producción artística de Arteta de comienzos de la década de los años 30. El pintor bilbaíno, que en aquellas fechas estaba preparando su oposición para la plaza de profesor que iba a tener lugar el 2 de agosto, mostró su agradecimiento al Museo de Arte Moderno por la compra -se trata de las dos primeras de obras de Arteta adquiridas con destino al museo, que un año después llegarían a ser expuestas en el Pabellón español en la Exposición Internacional de París junto a una importante selección de arte vasco de la colección-, y así se lo hizo saber a Manuel Losada ${ }^{64}$

62 AMBA: CD-1347-B

63 AMBA: MAM/M (1933: 1-2); CD-1253

64 AMBA: CD-1355; 1357; 1358; 1359 


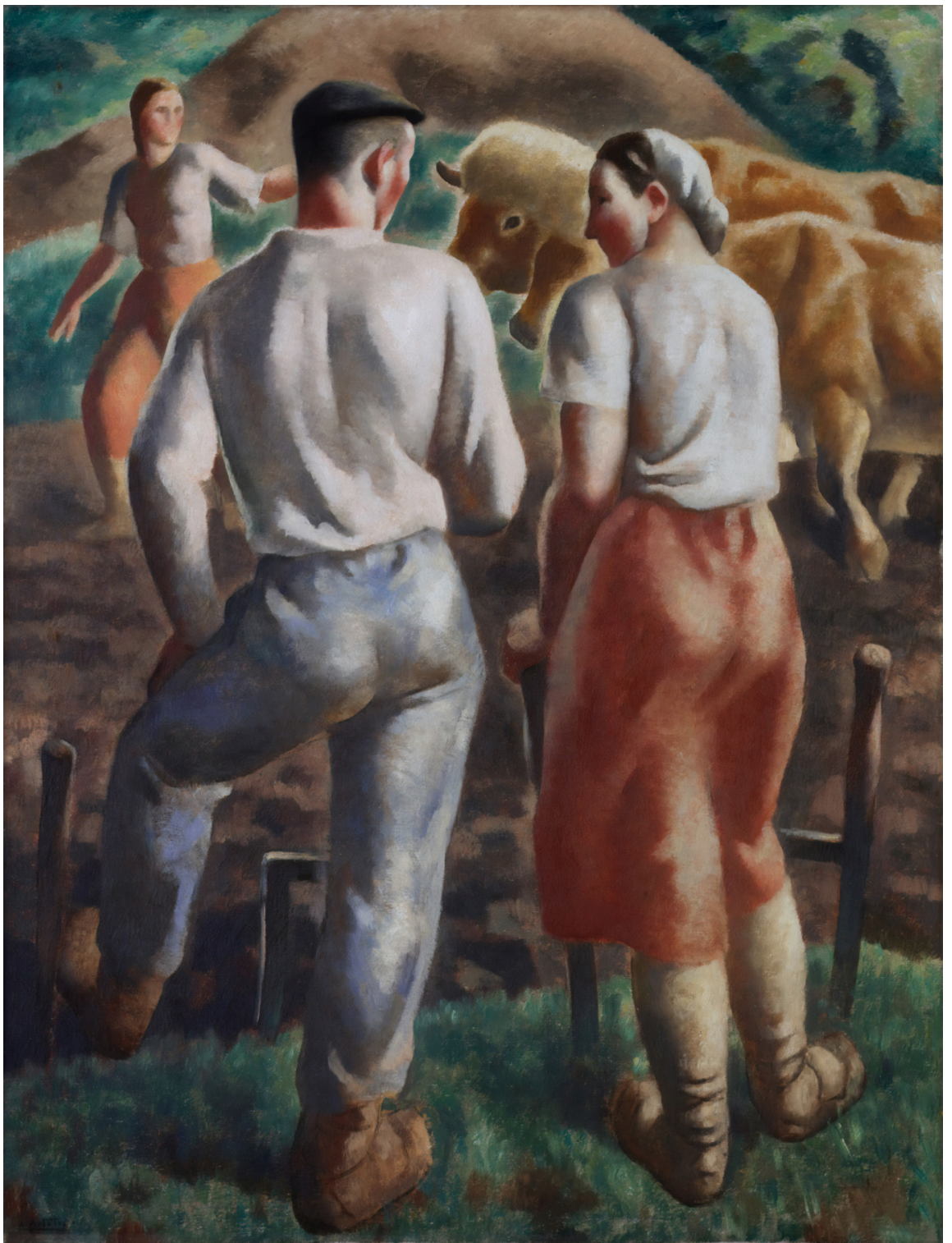

Fig. 10: Layadores o Idilio rústico, Aurelio Arteta, c. 1930-35; n.o inv. 82/167. Museo de Bellas Artes de Bilbao
La trayectoria y el desarrollo autónomo del Museo de Arte Moderno de Bilbao se truncó en verano de 1936 con el estallido de la Guerra Civil, que supuso el fin de una época. Nacido del seno del Museo de Bellas Artes, de quien había heredado su colección inicial, tras cas tres lustros en los que recorrió su camino y completó sus fondos con criterios y recursos propios, volvió junto a su progenitor tras la contienda bélica en un nuevo edificio a partir de 1945, para enriquecer y fijar los fundamentos del actual Museo de Bellas Artes de Bilbao.

Antes de la fusión con el Museo de Bellas Artes, la colección del Museo de Arte Moderno fue, debido a cuestiones de seguridad y a razones políticas, trasladada a Francia donde participó de la mano del Gobierno Vasco en el exilio en distintas exposiciones que tenían como objeto dar a conocer el País Vasco en ciudades como París, Bruselas y La Haya junto a distintas iniciativas culturales con los grupos Elai-Alai y Eresoinka ${ }^{65}$. Por su parte, Aurelio Arteta, que vivía un momento de madurez creativa y cierto optimismo en el plano personal -su querido Museo de Arte Moderno le acababa de adquirir dos pinturas y se encontraba preparando las oposiciones de profesor-, sufrió de pleno las consecuencias de la guerra, que le llevaron a trasladarse desde el Madrid sitiado a Valencia, Barcelona y Biarritz respectivamente, hasta su exilio en México a partir de junio de 1939, donde falleció en un accidente de tranvía en noviembre de $1940^{66}$.

\section{CONCLUSIONES}

Tras las tensiones entre tradición y modernidad que vivió en su seno el Museo de Bellas Artes a lo largo de la década de los años 10, en 1924 abrió sus puertas el Museo de Arte Moderno de Bilbao como respuesta al impulso de una parte de la sociedad civil que apostó claramente por la creación y desarrollo de una colección artística pública de arte moderno y defendió que la cultura artística contemporánea había logrado cotas lo suficientemente elevadas -con la Exposición Internacional de Pintura y Escultura de 1919 como punto álgido del anhelo cosmopolita y del ambiente a favor de la modernidad- para que Bilbao contara con una institución autónoma que pudiera emanciparse de su progenitor y jugara un papel complementario al mismo.

65 Para un exhaustivo estudio de la evacuación, exilio y retorno de la colección del Museo de Arte Moderno de Bilbao durante la Guerra Civil española ver MUÑOZ J El museo ausente La evacuación del Museo de Arte Moderno de Bitboo durnte la Guerra Civit. (Leio), Universidad del Pás Vaco = Eus ea, 2017

66 Javier González de Durana ha estudiado la vida y obra de Aurelio Arteta durante su exilio entre 1936 1940 en GONZÁLEZ DE DURANA, J.: Guerra, exilio y muerte de Aurelio Arteta (1936-1940). Sevilla, Punto Rojo Libros, 2016. 
Partiendo de los postulados fundacionales del Museo de Bellas Artes, el nuevo Museo de Arte Moderno hizo suyos los ideales estéticos de los principales protagonistas de la cultura artística bilbaína contemporánea para conjugar las distintas sensibilidades y relatos de lo moderno. El elegido para dirigir el museo fue el pintor Aurelio Arteta, un artista comprometido con la modernidad que había participado en la creación de la Asociación de Artistas Vascos y que definió la orientación de la nueva institución sobre dos ejes estratégicos: una política de compras regular y la celebración de exposiciones temporales con objeto de obtener obras de jóvenes artistas para la colección.

Bajo la dirección de Arteta se proyectaron las Exposiciones de Artistas Vascongados -que tuvieron lugar en 1926, 1932 y 1934, y sirvieron para ingresar obras de los creadores locales emergentes- y del mismo modo, como continuación de la apuesta internacional definida con motivo del grupo de obras que ingresó el Museo de Bellas Artes procedentes de la Exposición Internacional de Pintura y Escultura, se fijó una política de adquisiciones que se decantó desde sus inicios por artistas nacionales e internacionales y perfiló su objetivo en obtener obras de autores no consagrados en el mercado junto a artistas de primera fila para lo que proyectó una política de ahorro.

Sin embargo, en seguida surgieron los problemas, y Arteta se vio forzado a dimitir en 1927 debido al malestar que de manera pública mostraron las autoridades del Ayuntamiento de Bilbao hacia la orientación que había tomado el Museo de Arte Moderno. La incomprensión de las instituciones ante sus criterios avanzados y las dificultades para salir de la crisis económica que había tenido lugar durante los primeros años de la década de los años 20 , limitaron en gran medida el crecimiento del museo, que a pesar de recuperar a la Junta de Patronato dimisionaria y a Aurelio Arteta en la dirección durante la década de los años 30 no pudo llegar a desarrollar sus objetivos debido a la escasez de recursos y al estallido de la Guerra Civil en 1936

En términos generales, los museos bilbaínos reflejaron y ayudaron a definir un tipo de plástica contraria a las corrientes académicas y a su vez conservadora, que compartía características comunes -tradición, modernidad, atención a lo local- y en cierta medida se identificaba con actitudes y aspiraciones novecentistas, en coincidencia con el canon definido por Juan de la Encina en La Trama del Arte Vasco (1919). En esencia, hicieron suya la concepción de modernidad hegemónica entre los creadores locales junto a los distintos artistas catalanes y demás pintores españoles considerados novecentistas que, a pesar de su significativa variedad estilística, apenas se desarrolló más allá de los lenguajes artísticos prevanguardistas.
Mientras el Museo de Bellas Artes reflejó entre 1914 y 1924 la confirmación y asimilación de lenguajes modernos acontecida en la plástica vasca durante finales del siglo XIX y las dos primeras décadas del siglo XX -desde el impresionismo hasta distintas tendencias postimpresionistas francesas, así como el simbolismo y el fauvismo, junto a la recuperación de la raíz moderna de la tradición española-, por su parte, entre 1924 y 1936 el Museo de Arte Moderno plasmó en su colección, bajo el liderazgo de Aurelio Arteta y con una mayor y más avanzada relación con el arte local que en los círculos madrileños y catalanes, la asimilación atemperada e indirecta de lenguajes vanguardistas como el cubismo y el retorno al orden de la modernidad acontecido a nivel europeo, y se atuvo a los lenguajes realistas vigentes en el foco bilbaíno, al tiempo que durante los años 30 San Sebastián vivía el auge de la vanguardia.

En 1936 el Museo de Arte Moderno contaba con una colección que ascendía a alrededor de 250 obras entre pinturas, dibujos, grabados, esculturas y demás piezas artísticas. Con los fondos procedentes de la sección del Museo de Bellas Artes como punto de partida, durante su trayectoria como institución autónoma entre 1924 y 1936 el Museo de Arte Moderno de Bilbao ingresó ejemplares de artistas vascos consagrados -Francisco Iturrino, Darío de Regoyos, Gustavo de Maeztu, Francisco Durrio-, y tras su fracasada intención inicial de abrirse al mercado internacional, destaca su clara apuesta por los artistas más jóvenes que despuntaron a lo largo de la década de los años 20 -José María Ucelay, Juan de Aranoa, Jesús Olasagasti, Jenaro Urrutia, Benito Bikandi-, así como por ciertos distinguidos artistas nacionales con significativa presencia en el sistema artístico vasco Daniel Vázquez Díaz y Joaquim Sunyer-. Fiel a su espíritu de mantener un carácter de constante contemporaneidad, a pesar de recoger en su reglamento la intención de mostrar preferencia por las escuelas de vanguardia y explicitar su obligación de correr todos los riesgos, hasta el de la equivocación, al Museo de Arte Moderno no llegaron ejemplos de artistas como Celso Lagar, Joaquín Torres García, Robert y Sonia Delaunay o Nicolás Lekuona, que mostraron sus obras en distintas exposiciones en Bilbao entre 1914 y 1936.

El Museo de Bellas Artes y el Museo de Arte Moderno convivieron y se complementaron mutuamente en el Bilbao anterior a la Guerra Civil, logrando reunir un grupo de obras excepcionales, muchas de ellas piezas clave en las colecciones actuales. La coexistencia de dos museos autónomos, que constituían las dos caras de la misma moneda, tuvo lugar solamente durante algunos años, dado que inmediatamente después de la Guerra Civil volvieron a compartir sede y en poco tiempo llegaron a constituir una sola institución, si bien la existencia y el breve desarrollo del Museo de Arte Moderno, con Aurelio Arteta a la cabeza, perfiló la vocación y orientación del futuro Museo de Bellas Artes de Bilbao como una institución ligada a la creación contemporánea de su contexto más cercano. 


\section{BIBLIOGRAFÍA}

Catálogo Exposición de Arte. III Congreso de Estudios Vascos. Gernika. Septiembre 1922, Excma. Diputación de Vizcaya, Imprenta moderna Medinabeitia y Zallo, Gernika, 1922.

Exposición de Artistas Vascongados. (Bilbao : Museo de Arte Moderno de Bilbao), 1926.

Segunda Exposición de Artistas Vascongados. (Bilbao, Museo de Arte Moderno de Bilbao, 1932)

Guía Artistas Vascos. Museo de Bellas Artes de Bilbao. Bilbao, Museo de Bellas Artes de Bilbao, 2008

Novecentismo y Vanguardia (1910-1936) en la colección del Museo de Bellas Artes de Bilbao. Bilbao, Museo de Bellas Artes de Bilbao, 2009.

ALZURI, M. Juan de la Encina : una trama para el arte vasco. Bilbao, Muelle de Uribitarte Editores, 2013

BENGOECHEA, J.: Museo de Bellas Artes de Bilbao. Bilbao, La Gran Enciclopedia Vasca, 1978.

DE LA ENCINA, J.: Pintores vascos. Comentarios sueltos. Bilbao, El Tilo, 1997.

FERNÁNDEZ DE LA SOTA, J.: Aurelio Arteta: los trabajos y los días. Bilbao, Muelle de Uribitarte, 2015

GONZÁleZ DE DURANA, J.: Aurelio Arteta. Madrid, Fundación Mapfre, Instituto de Cultura, 2008.

GONZÁLEZ DE DURANA, J.: “Francisco Durrio y su colección de gauguins” en Francisco Durrio, 1868-1940: sobre las huellas de Gauguin. Bilbao, Bilboko Arte Ederren Museoa = Museo de Bellas Artes de Bilbao, 2013, pp. 195-234.

GONZÁlEZ DE DURANA, J.: Guerra, exilio y muerte de Aurelio Arteta (1936-1940). Sevilla, Punto Rojo Libros, 2016.

JIMÉNEZ-BLANCO, M. D.: El coleccionismo de arte en España. Una aproximación desde su historia y su contexto. Barcelona, Cuadernos Arte y Mecenazgo, n. 2, Fundación Arte y Mecenazgo, 2013.
KORTADI, E.: “Aurelio Arteta, entre la Renovación y las Vanguardias" en Aurelio Arteta: una mirada esencial, 1879-1940. Bilbao, Museo de Bellas Artes de Bilbao, 1998, pp. 37-92.

MANTEROLA, I.: Hermes y los pintores vascos de su tiempo. Bilbao, Bizkaiko Foru Aldundia, Kultura Saila = Diputación Foral de Bizkaia, Departamento de Cultura, 2006.

MANTEROLA, I.: Trama e hilos sueltos: dialogo entre dos colecciones de arte vasco. VitoriaGasteiz, Museo de Bellas Artes de Álava, 2014.

MOYA, A. "Tradición y modernidad. Arte y artistas vascos en el Museo de Bellas Artes y Arte Moderno de Bilbao", Bidebarrieta. Revista de humanidades y ciencias sociales de Bilbao, n. ${ }^{\circ}$ 2, II Symposium de Bilbao 700 años de memoria. Arte, Patrimonio monumental y ciudad, 1997, pp. 89-105.

MUÑOZ, J. El museo ausente. La evacuación del Museo de Arte Moderno de Bilbao durante la Guerra Civil. (Leioa), Universidad del País Vasco = Euskal Herriko Unibertsitatea, 2017.

MUR, P.: La Asociación de Artistas Vascos. Bilbao, Museo de Bellas Artes de Bilbao : Caja de Ahorros Vizcaína, 1985.

ONANDIA, M.: Museo de Bellas Artes de Bilbao: los orígenes de una colección. Las colecciones del Museo de Bellas Artes y el Museo de Arte Moderno de Bilbao. 1908-1936 (Tesis doctoral). Bilbao, Universidad del País Vasco-Euskal Herriko Unibertsitatea, 2017.

SÁENZ DE GORBEA, X.: “Crónica de hechos y prácticas artísticas en Vizcaya. 1931/1937”, en Arte y artistas vascos de los años 30. Entre lo individual y lo colectivo. San Sebastián, Diputación Foral de Gipuzkoa, 1986

VÉLEZ, E.: Historia del Museo de Bellas Artes de Bilbao (Tesis doctoral). Madrid, Universidad Complutente, Servicio de Publicaciones, 1992.

ZUGAZA, M. "Definir lo moderno. La formación de una colección de arte contemporáneo" en De Picasso a Bacon. Arte contemporáneo en las colecciones del Museo de Bellas Artes de Bilbao. Segovia, Museo de Arte Contemporáneo Esteban Vicente, 1999. 